\title{
The art of limb salvage in musculoskeletal oncology
}

\author{
René P.H. Veth*a , Quirinus G.C.M. van Hoesel ${ }^{b}$, Jos P.M. Bökkerink ${ }^{c}$, Jaap Hoogenhout ${ }^{d}$, \\ Maciej Pruszczynski ${ }^{\mathrm{e}}$
}

\begin{abstract}
${ }^{a}$ Department of Orthopaedics, University Hospital, Nijmegen, The Netherlands bivision of Medical Oncology, University Hospital, Nijmegen, The Netherlands 'Division of Paediatric Oncology, University Hospital, Nijmegen, The Netherlands ${ }^{\mathrm{d}}$ Department of Radiotherapy, University Hospital, Nijmegen, The Netherlands 'Department of Pathology, University Hospital, Nijmegen, The Netherlands
\end{abstract}

Accepted 1 November 1994

\section{Contents}

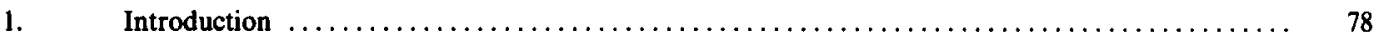

1.1. A short history of surgery in musculoskeletal oncology $\ldots \ldots \ldots \ldots \ldots \ldots \ldots \ldots \ldots, 78$

1.2. Improvements in chemotherapy for musculoskeletal oncology $\ldots \ldots \ldots \ldots \ldots \ldots \ldots \ldots \quad 78$

1.3. Improvements in radiation for musculoskeletal oncology $\ldots \ldots \ldots \ldots \ldots \ldots \ldots \ldots \ldots, 79$

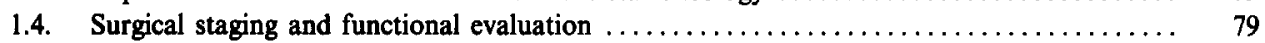

1.5. The goal of limb salvage $\ldots \ldots \ldots \ldots \ldots \ldots \ldots \ldots \ldots \ldots \ldots \ldots \ldots \ldots \ldots \ldots \ldots \ldots \ldots$

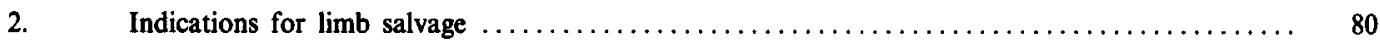

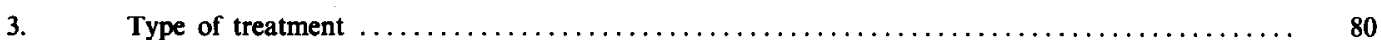

3.1. Role of grading and tumor biology $\ldots \ldots \ldots \ldots \ldots \ldots \ldots \ldots \ldots \ldots \ldots \ldots \ldots \ldots \ldots \ldots$

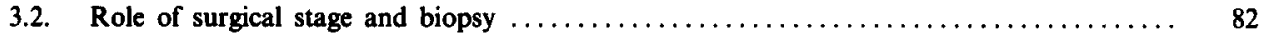

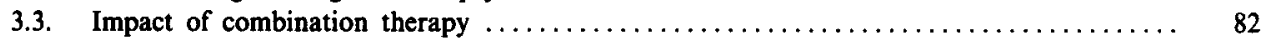

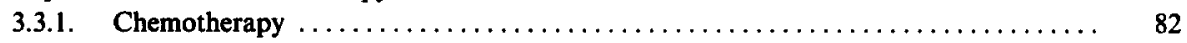

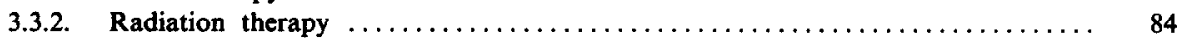

3.3.2.1. Radiation therapy of bone tumors $\ldots \ldots \ldots \ldots \ldots \ldots \ldots \ldots \ldots, 84$

3.3.2.2. Radiation therapy of soft tissue sarcomas $\ldots \ldots \ldots \ldots \ldots \ldots \ldots \ldots . \ldots 4$

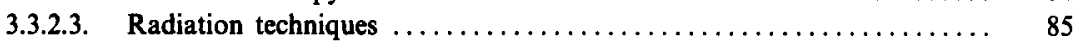

3.3.3. Surgical adjuvant therapy at the time of operation $\ldots \ldots \ldots \ldots \ldots \ldots \ldots \ldots \ldots \ldots \ldots$

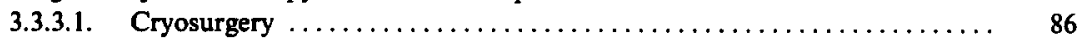

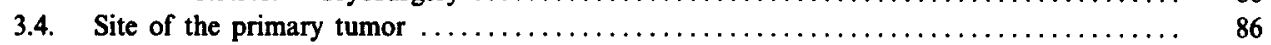

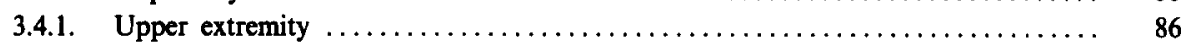

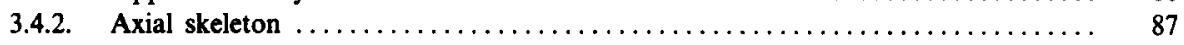

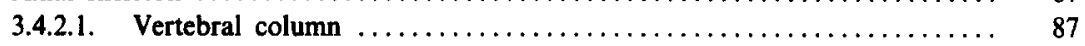

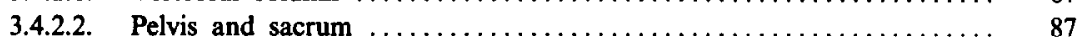

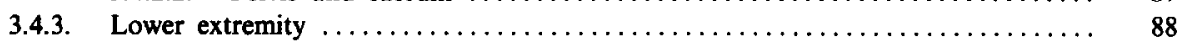

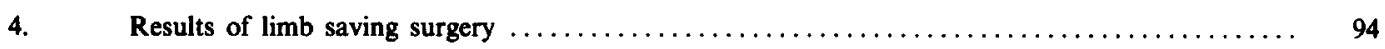

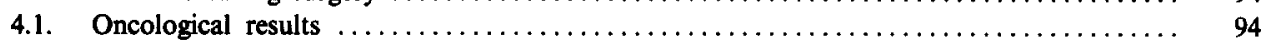

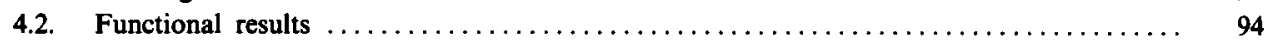

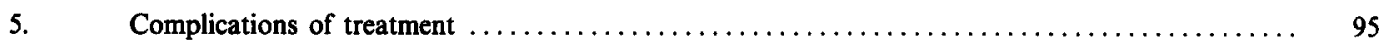

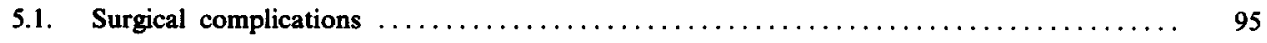

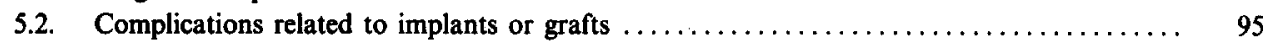

\footnotetext{
* Corresponding author, 800 Orthopaedic Department, P.O. Box 9101, 6500 HB Nijmegen, The Netherlands. Tel. (+31-80) 617378; Fax. $(+31-80)$ 540230.
} 


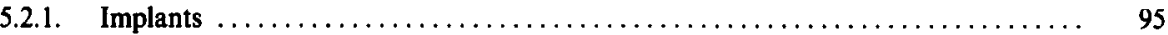

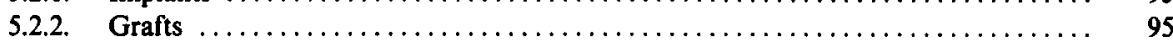

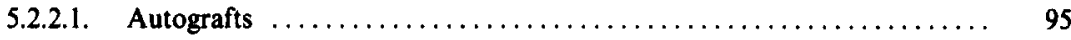

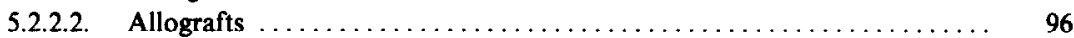

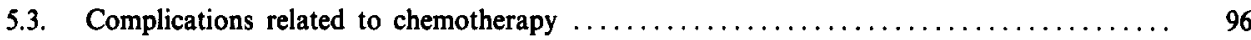

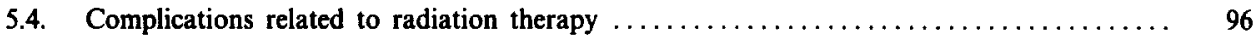

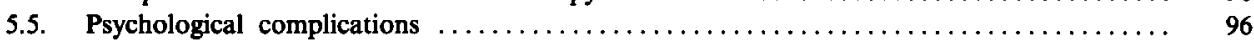

6. Closing remarks and prospects for the future $\ldots \ldots \ldots \ldots \ldots \ldots \ldots \ldots \ldots \ldots \ldots \ldots \ldots \ldots$

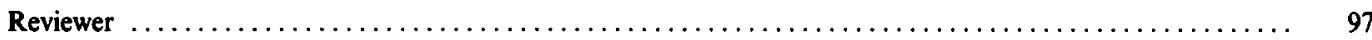

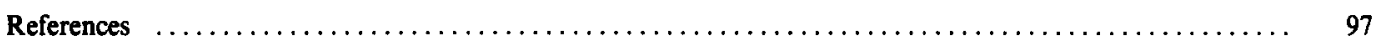

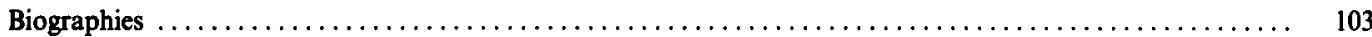

\section{Introduction}

\subsection{A short history of surgery in musculoskeletal oncology}

In the 19th century the primary choice of surgical treatment in musculoskeletal oncology was amputation.

This choice was based on the observation that resections were frequently followed by local recurrences and that the mortality rate after resection was high [1]. Before the 1970 s treatment of osteogenic sarcoma consisted of radiotherapy and amputative surgery in many cases, according to the protocol, as described by Cade [2]. It took surgeons more than half a century to see that reconsideration of this conduct was desirable. Surgery had improved as well as the skills of anaesthesiologists, pathologists and radiologists. It seemed feasible to try to preserve a limb or joint in cases [3-5] where limb salvage would not cause more risk to life than other types of treatment, and in palliative cases such as metastatic bone disease.

Just after World War II, John Scales in the United Kingdom started to develop megaprostheses for reconstruction of large defects after musculoskeletal surgery [5]. In 1958 Merle d'Aubigne [6] described a special type of resection-arthrodesis, which he used in 'diaphysealepiphyseal' tumors around the knee. Limb saving surgery was born. Nilsonne [7] had the courage to treat patients with a tumor of the pelvis with a less mutilating operation compared to hemipelvectomy. He performed a resection of the periacetabular region, kept the leg intact in situ and called this an 'internal hemipelvectomy'. Ottolenghi [8] and Mankin [9] developed a type of reconstruction in which they made use of homogenous bone allografts. This type of treatment was based on the observations of Chase and Herndon [10] who had studied the fate of autogenous and homologenous bone grafts.

Because reconstruction with the aid of prostheses or allografts was expensive, Pho [11] started to use vascularized autogenous bone grafts for reconstruction of defects. However, these types of reconstruction as part of limb saving surgery would never have reached the modern state of the art without the major steps forward which took place in radiology [12], chemotherapy [13-15], radiotherapy [16,17] and oncologic staging [13]. Codman's [18] triangle as an indication of rapid growth by extracortical spread has been known since 1926 and Lodwick's [19] classification of radiological patterns of bone destruction in geographic, permeative and moth-eaten lesions has been used since 1966. Angiography was able to detect vascular involvement and soft tissue extension, but is nowadays seldom used for this purpose. CT scans and MRI are replacing angiography for this purpose [20].

Skeletal technetium scintigraphy [21] was, and is, extremely useful in the detection of primary and metastatic bone tumors. However, the uptake of a bone seeking isotope is non-specific and non-diagnostic.

The introduction of computed tomography [22] in musculoskeletal oncology in 1979 enhanced the visualisation of the extension of tumor in the medulla and soft tissues. This was a major step forward.

Since 1977 nuclear magnetic resonance [23] has been used for imaging purposes. It appears to be extremely useful for defining the intramedullary extent, soft tissue spread, presence of skip-lesions and response to chemotherapy. Although its value for diagnostic purposes is beyond doubt, this technique is still complementary to other imaging techniques [24].

Diagnostic strategy in bone and soft tissue tumors has become extremely important in the treatment of these tumors [25].

\subsection{Improvements in chemotherapy for musculoskeletal oncology}

Before the advent of chemotherapy the outcome for patients with musculoskeletal malignancies was very poor. Combined surgical and radiotherapeutic therapy was able to cure only $10 \%$ of patients with Ewing's sarcoma [26], $20 \%$ of patients with osteosarcoma [27], and 
$14 \%$ of children with soft tissue tumors, especially rhabdomyosarcoma [28]. Between 1955 and 1970, several workers demonstrated objective tumor regression after the administration of new chemotherapeutic agents, such as actinomycine D [29], cyclophosphamide [30], vincristine [31], adriamycine [32-34], and high-dose methotrexate [35-37]. Single agent therapy with these agents was able to induce a percentage of complete and partial responses in the order of $20-50 \%$. Adjuvant chemotherapy using combinations of these agents began after 1970. The most important initial chemotherapeutic schemes consisted of a combination of vincristine, actinomycine $\mathrm{D}$ and cyclophosphamide in patients with soft tissue tumors and Ewing's sarcomas [38], and highdose methotrexate in patients with osteosarcoma [39].

After 1970 multi-institutional trials $[40,134]$ recruited large numbers of patients with the aim of answering therapeutic and prognostic questions within a reasonable period of time. Examples of the multicenter study groups are the Children's Cancer Study Group (CCSG), Intergroup Rhabdomyosarcoma Study (IRS), Intergroup Ewing's Sarcoma Study (IESS), European Intergroup Cooperative Ewing's Sarcoma Study (EICESS), European Osteosarcoma Intergroup (EOI) [41], Cooperative Osteosarcoma Study (COSS), MultiInstitutional Osteosarcoma Study (MIOS), several studies of the International Society of Pediatric Oncology (SIOP), and several national groups. New chemotherapeutic schemes from these international study groups and the introduction of new drugs, such as cisplatin, ifosfamide and etoposide, resulted in further improvements in the prognosis of patients, and especially of children with musculoskeletal malignancies. With the introduction of preoperative (neoadjuvant) chemotherapy, new prognostic factors became available; tumor necrosis after chemotherapy in osteosarcoma and Ewing's sarcoma is a particularily important prognostic factor.

Moreover, preoperative chemotherapy was able to reduce the tumor volume in a large number of cases and was an important prerequisite for preservative and limb saving surgery. In exceptional cases, tumor resection could be omitted after chemotherapy, because of complete necrosis of the tumor [42].

\subsection{Improvements in radiation for musculoskeletal oncology}

The treatment of malignant bone tumors and soft tissue sarcomas requires a multimodal approach with carefully designed strategies.

The results of radiation therapy improved due to more accurate information obtained by imaging techniques with contrast enhanced computed tomography and preferentially gadolinium enhanced magnetic resonance imaging [25].
Three-dimensional treatment planning and the use of conformal radiation therapy utilising multileaf collimators increased the homogeneity of dose in the different sections of the treatment volume and decreased the irradiated volume of the surrounding normal tissues.

Intraoperative radiation therapy was developed and is nowadays under investigation, especially in comparison to external beam therapy.

In Ewing's sarcomas, the application of hyperfractionated accelerated radiation therapy may contribute to a higher local control rate and myelo-ablative radiochemotherapy may be advantageous in multifocal disease.

In advanced osteosarcomas, the efficacy of new fractionation schemes combined with radiosensitizing drugs may be advantageous.

For soft tissue sarcomas the benefit of interstitial brachytherapy in selected cases has been demonstrated.

\subsection{Surgical staging and functional evaluation}

Historically, an adequate surgical procedure has been the most effective means of treating the majority of musculoskeletal sarcomas. Nowadays chemotherapy alone is effective as a solitary treatment without surgery and/or radiotherapy in selective cases of childhood soft tissue tumor with histologically proven complete response [42]. In all other cases, chemotherapy has to be followed by extensive local treatment. Chemotherapy in combination with local radiotherapy and without surgical tumor excision is only effective in a number of cases of childhood soft tissue tumors with good initial response and may be the only possible therapy in some cases of Ewing's sarcoma with tumors inaccessible for surgical treatment. However, in most cases of musculoskeletal sarcomas surgery remains the essential step in local and systemic tumor control.

Many institutes around the world nowadays treat patients with musculoskeletal tumors. In order to compare the results of treatment and to share the know-how it is obligatory to speak the same oncologic language. For this purpose a staging system is an important tool. It was William F. Enneking [43,44], who developed a staging system which primarily encompassed the biologic behavior of the tumor. This was a major step forward. The achievements of radiology and pathology played an important role in the system, but nowadays, with increasing impact, the improvements in tumor science are accomplished by cytogenetics, molecular biology and flow cytometry in addition to this staging system.

The staging system guides the surgeon and the interdisciplinary team to the best type of treatment for the individual patient and it enables its supporters to communicate with one another, which obviously is the best way to improve the global results of treatment in musculoskeletal oncology. 
In addition to the staging system, Enneking developed a system for the functional evaluation of patients who underwent limb saving surgery $[45,46]$. This system was adopted by those concerned with musculoskeletal tumors and is used all over the world. A way was found to discuss the outcome of limb salvage, which undoubtedly in the future will improve the results of this type of treatment.

\subsection{The goal of limb salvage}

The goal of limb salvage in musculoskeletal oncology is the cure and the restoration of functional integrity of patients with a malignant tumor of bone or soft tissue by a combination of surgery and adjuvant therapy, without performing mutilating procedures. Amputation derived methods, like rotation plasty [47-49], should not be included. All methods of treatment that avoid amputation, disarticulation or hemipelvectomy, without compromising the oncological result can be used to achieve the purpose of limb salvage. Limb saving surgery should not only pursue a good oncologic and functional result, but it should also strive after a good psychological outcome.

In cases of soft tissue extension, limb salvage should only be recommended when resection of the tumor with optimal oncologic margins is able to preserve good functional results.

\section{Indications for limb salvage}

The indications for limb saving surgery in musculoskeletal oncology refer to all malignant bone and soft tissue tumors of the extremities and axial skeleton that are amenable to non-mutilating surgery. As the purpose of this type of treatment is the cure of the patient, one should definitely include the treatment of metastases of the primary tumor.

Thus the indications for limb salvage $[50,51]$ are:

- Tumors which are located in the extremities and/or axial skeleton;

- Where optimal oncologic surgical margins are feasible;

- Where the soft tissue extension is moderate;

- Where the neurovascular bundles are not compromised;

- Where metastases are absent or amenable to optimal curative treatment;

- In patients, who are in an optimal condition;

- In whom there are no signs of infection; and

- Who are capable of good cooperation during the treatment.

From limb preserving surgery are excluded patients with sarcomas of the foot, large anaplastic sarcomas, re- currence following adequate resection, and with severe irradiation damage. Those patients are mostly best treated by amputation [52].

The fact that, for limb salvage, the neurovascular bundle should not be invaded by the tumor reflects the starting point that a limb without vessels and/or nerves cannot function on an adequate basis. It should, however, be kept in mind, that there are some exceptions to this rule, for instance invasion involving the peroneal nerve and the anterior tibial vessels. Although a partial or total resection of the peroneal nerve will often result in sensomotory disturbances, it will not create complete disability and it therefore may be included in common practice of limb salvage. Sacrifice of the anterior tibial vessels does not preclude restoration of function in patients with tumors of the proximal tibia. Sacrifice of the sciatic or the median nerve would definitely prevent adequate recovery and therefore contaminations of these nerves are excluding criteria for limb salvage.

Optimal surgical margins are $6 \mathrm{~cm}$ of normal bone around the bony margins of a bone tumor and $2 \mathrm{~cm}$ of normal soft tissue around its soft tissue extension [50,51]. In soft tissue tumors margins of $2-3 \mathrm{~cm}$ should be accomplished [53].

These margins are obligatory in tumors which are, at the time of surgery, highly aggressive and in which chemotherapy could not be instituted or which did not respond adequately to chemotherapy. If, however, a malignant tumor appears to be sensitive to chemotherapy, one may accept smaller margins, for instance $3 \mathrm{~cm}$ of bone and $1 \mathrm{~cm}$ of soft tissues. However, the present diagnostic tools, including both radiological and histological methods, are not very reliable regarding the impact of chemotherapy on a tumor.

A moderate soft tissue extension means that, after the resection of the tumor.$\quad$ with observations of the optimal margins - a restoration of active function is still possible. Reconstruction of a distal femur and knee joint in a patient in whom the active muscles have been resected is useless. This is an example of bad practice in limb salvage. In cases where metastases are present one should only consider limb saving surgery when, after chemotherapy and metastectomy, adequate tumor reduction and tumor necrosis has been demonstrated. In all remaining cases of metastases one should not pursue limb salvage. Optimal condition, absence of infection and good cooperation of the patient are selecting criteria, which not only hold for the surgical part of the treatment, but also for chemotherapy.

\section{Type of treatment}

\subsection{Role of grading and tumor biology}

In the treating team, a pathologist plays a central role in diagnostic and prognostic evaluation of musculo- 
skeletal tumors [54]. His task is to classify and grade the tumors and to assess therapy effects if necessary [55]. Unfortunately, there is no grading system accepted world-wide, although the overall tendency is to employ a three-grade system, which is the most reproducible and the best way to predict survival [56,57]. Limitation of grading is connected with structural variations in different areas of the same tumor. Grading can be misleading with tumors of uncertain histogenesis [56]. The predictive significance of various prognostic parameters varies in different types of musculoskeletal tumors [58-60].

For soft tissue tumors the number of mitoses and extent of necrosis seem to be the most important parameters in predicting biological behavior $[56,61]$. In limb preserving treatment inadequate surgical margins predict for local recurrence, distant recurrence and overall survival [53]. Ancillary procedures such as special stains, electron microscopy and immunohistochemistry are essential in the tumor typing. In many cases electron microscopy is required particularly to differentiate between sarcoma and malignant melanoma, malignant lymphoma or metastatic carcinoma as well as between various spindle cell or round cell tumors. The main limitation of electron microscopy as a diagnostic tool is connected with small sampling and paucity of specific ultrastructural features [56]. Immunohistochemistry permits high diagnostic accuracy, but achieved results must be interpreted in the context of light microscopic morphology to prevent interpretation errors [52]. Immunohistochemical markers are not only used to detect cell lineage or tissue of origin of specific tumor, but also to assess malignant potential of neoplasms. Using antibody Ki67 or staining proliferating cell nuclear antigen (PCNA), the proliferating activity in almost the entire cell cycle can be revealed and quantified $[62,63]$. Those methods are superior to histologically determined mitotic index, which is sometimes questioned for its insufficient reliability [52].

When the interdisciplinary treating team selects a particular therapy for a patient, it should not only take into account the radiological and histopathological features of the tumor, but also its response to neoadjuvant therapy [64] and its cytogenetic and flow cytometric characteristics. Many musculoskeletal tumors show clonal chromosomal abnormality, which will help to delineate several of these neoplasms [65]. Specific chromosomal translocations of diagnostic significance were found in synovial sarcoma [66], myxoid liposarcoma [67], alveolar, undifferentiated and embryonal rhabdomyosarcoma $[68,69]$, Ewing's sarcoma, PNET, Askin tumor [70-72] and malignant fibrous histiocytoma [65,73-75]. Ewing's sarcoma, PNET and Askin tumor all show the same chromosomal error and this phenomenon may be indicative of similar biological behavior and common histogenesis [72,74]. Routine tumor typing and grading is mainly based on subjective interpretation of microscopical features and some inter-observer discrepancies in the diagnosis of musculo-skeletal tumors are well-known [52,76]. There is growing evidence that molecular pathological techniques can not only supplement conventional methods, but also improve tumor assessment providing objective information that cannot be obtained in any other way [77].

The treating team must be aware of the capabilities and limitations of a molecular approach to oncological diagnosis.

Flow cytometric DNA analysis on fresh or paraffin embedded tumor samples is a reproducible and clinically useful quantitative method characterizing malignant potential [78], although it does not allow clear separation between benign and malignant tumors, and sporadically can demonstrate misleading results [52]. In musculoskeletal tumors it can be used as a reliable prognostic indicator, can follow the progress of disease and determine the effect of therapy $[56,79,80]$. There is a good correlation between grade and ploidy of soft tissue tumors [81]. Regardless of histogenetic type, it appears that benign and low grade malignant soft tissue tumors are diploid and high grade malignant tumors in general are aneuploid [79] with the exception of epithelioid sarcoma [82].

DNA aneuploidy in musculoskeletal tumors is a strong independent negative prognostic factor $[59,76,83,84]$.

DNA content and tumor size are also independent prognostic factors for metastases and can discriminate between patients with a good and with a poor prognosis after surgical treatment, and can help to select high-risk patients for further adjuvant therapy [76,83]. Recently a good correlation has also been found between cytogenetic abnormalities and DNA ploidy in benign, borderline malignant, and malignant soft tissue tumors $[81,85]$.

No histological parameters predicted chemosensitivity in soft tissue tumors, and flow cytometric estimates of cell proliferation were the only pathologic features in initial biopsy that predicted subsequent response to chemotherapy [86].

In chondrosarcomas ploidy determination gives significant prognostic information even better than that obtained by conventional histological grading. Diploid chondrosarcomas show a significantly more favorable prognosis than hyperploid, which have been associated with early metastases and death $[60,87]$. The vast majority of high grade osteosarcomas are non-diploid $[59,84,85]$.

Present molecular methods used in oncology are expensive and time-consuming, but it can be expected that in the future technical improvement and automatization will simplify and increase the use of molecular diagnosis. 
Gadolinium enhanced MRI [88] and magnetic resonance spectroscopy [89] are becoming valuable tools in determining the response of osteosarcoma to chemotherapy. Positron emission tomography [90] may also be of value for evaluating tumor metabolism. These are examples of diagnostic tools which increase insight into the biological behavior of a tumor. Each institute that treats patients with bone and soft tissue tumors should preside over divisions that are able to perform these diagnostic procedures. Perhaps one may conclude that centres that do not have access to the majority of these facilities, should not treat this type of patient.

\subsection{Role of surgical stage and biopsy}

It has been emphasized before that surgical staging is essential in order to treat a patient in an optimal way. Physical examination, laboratory studies and radiological evaluation including MRI are essential for this purpose. CT scanning of the lung is a valuable tool for detection of lung metastases in early phase. In highly vascularized tumors or in tumors of the pelvis one may consider angiography or digital subtraction angiography. Also, in tumors of the pelvis, a urography may be helpful in delineating the ureter from the tumor.

According to the Enneking staging system [43,44], malignant tumors are graded by the histological pattern, the radiological appearance and the clinical course. Advanced techniques, which give information on the biological behavior of the tumor, should nowadays be included as well as biochemical analysis. Low grade tumors correspond with Broder's class I and II, high grade tumors with Broder's class III and IV. Intracompartmental sites should be distinguished from extracompartmental; this is essential in order to choose the proper margins at the time of operation.

In the system, all tumors that develop metastases are graded in the same way.

In addition to the grading of the tumor, the Enneking system also provides for a definition of the type of margin which is desirable or should be achieved at operation. Four planes of dissection are distinguished [44,91], each of which gives a different result with respect to residual disease. As the Enneking system is by now in use all over the world, we will not go into any further detail. For those who are not familiar with this system however, we strongly advocate reading the referred papers.

In almost all cases of bone and soft tissue malignancies, a biopsy [91-93] is taken somewhere along the preoperative tract. In the past, when amputation was the treatment of choice in these tumors, the site of biopsy was not always important. At present, knowing that $70 \%$ of all malignant bone and soft tissue tumors can be treated by limb salvage, it is essential to choose the proper site of the biopsy [94]. The biopsy scar must be wide- ly excised with the specimen. The biopsy scar should be as small as possible in order to avoid a 'waste of tissue' resection, the biopsy should not contaminate the neurovascular bundle and haematoma should be avoided $[44,50]$. The biopsy should be taken in line with the definite resection [93], which implies that it should be performed by the surgeon who will perform the resection or excision. Frozen sections may be helpful to determine whether a representative viable tumor sample has been obtained for special procedures and to yield satisfactory permanent paraffin sections for interpretation [93]. Cultures may be desirable in cases where infection may be present [44]. Haematoma due to biopsy can be prevented by packing the biopsy tract with gel-foam or bone cement [44].

In some centers interest has been renewed in frozen section diagnosis followed by immediate surgery. Although its expected advantage is decrease of tumor dissemination and contamination if a tourniquet has been used, the increased survival after this procedure has not been proven [95].

There is a current trend to perform needle biopsies instead of an open biopsy.

This strategy of performing needle biopsies is certainly valid for those who seek the optimal biopsy scar, in relation to the line of excision. Although in centres with a lot of experience with sarcomas, multiple core biopsies can often provide adequate diagnostic material, aspiration cytology is not sufficient [96]. It can be used, however, in documenting recurrent or metastatic disease once a primary diagnosis has been established [57]. The amount of tissue which should be obtained from the biopsy should however correspond with the wishes of the pathologist and moreover with the need to perform more advanced tests like DNA flow cytometry, electron microscopy, application of cell markers and cytogenetic assays. All these methods are essential for a proper prediction of the biological behavior of the tumor and should not be hampered by a needle biopsy, which provides an insufficient amount of tumor tissue. Pre-biopsy consultation of the pathologist, together with the attending radiologist, may be of value in this respect. Such discussions often embark on the necessity to take biopsies from one point of different bone and/or soft tissue parts of the tumor.

\subsection{Impact of combination therapy}

\subsubsection{Chemotherapy}

Although the optimal chemotherapeutic schedule in the treatment of Ewing's sarcoma remains to be established, convincing data from the IESS-I study have shown the superiority of a four-drug regimen with vincristine, actinomycine $\mathrm{D}$, cyclophosphamide and adriamycine (VACA) over a three-drug regimen without adriamycine in terms of event free survival ( $74 \%$ versus 
54\% EFS) and also the effectiveness of local control (96\% versus $86 \%$ ) [97]. Moreover, the IESS-II study demonstrated the superiority of high-dose VACA versus moderate-dose VACA [98]. The site of the tumor proved to be of prognostic importance (distal versus proximal versus central) in the CESS- 81 and the Italian study $[99,100]$, and patients treated with chemotherapy, surgery and radiotherapy fared better than patients treated with surgery or radiotherapy in combination with chemotherapy [99-101]. However, the interpretation of the role of surgery compared to the role of radiation therapy with respect to outcome is difficult to assess due to the fact that smaller tumors which have a better prognosis are more amenable to surgery.

Prognostic parameters in the CESS-81 study proved to be a tumor volume of $<100 \mathrm{ml}(80 \%$ versus $32 \%$ EFS) and a good histologic response, i.e., less than $10 \%$ viable tumor cells detectable in the surgical specimen $(79 \%$ versus $31 \%$ EFS) [99]. The CESS-86 study [101] demonstrated clearly that the introduction of ifosfamide (VAIA instead of VACA) was especially advantageous for large (>100 ml) and central tumors with an EFS of $43 \%$ in CESS-81 and an EFS of $67 \%$ in CESS-86. In this study tumor volume was no longer a risk factor. The results of the two English trials also demonstrated a better outcome for all patients (including patients with metastases at diagnosis) treated with ifosfamide compared to cyclophosphamide ( $51 \%$ versus $34 \% \mathrm{EFS}$ ), however the outcome for patients with metastases at diagnosis and patients with central tumors was not statistically different [102]. Based on these CESS and UKCCSG studies with respect to the beneficial effect of ifosfamide, the new European EICESS-92 study is conducting a randomized trial in standard-risk patients (tumor volume $<100 \mathrm{ml}$ ) comparing VACA versus VAIA after 4 preoperative VAIA courses and local therapy. Based on a phase II study with ifosfamide and etoposide with significant responses even in children resistant to cyclophosphamide [103], although not confirmed by others in a non-randomized study [104], high-risk patients $(>100 \mathrm{ml})$ in the EICESS-92 study are randomized to receive VAIA with or without etoposide.

Preoperative chemotherapy has been used with increasing frequency in the management of patients with osteosarcoma in the past decades [105-108]. A large number of international trials with a large variation of chemotherapeutic agents has demonstrated the efficacy of chemotherapy in patients with osteosarcoma $[109,110]$. The role of preoperative chemotherapy in osteosarcoma is especially important, because the biologic behaviour of this tumor causes it to be explicitly accessible for limb saving surgery [105]. In contrast to high grade primary osteosarcoma, the response to chemotherapy of postirradiation sarcoma is worse [111]. However, the amount of active drugs available for osteosarcoma is limited. Single-agent therapy with high- dose methotrexate, cisplatin, adriamycine or ifosfamide has resulted in over $20 \%$ partial and complete responses as proven in phase II trials [32]. The role of high-dose methotrexate is controversial. Its efficacy was not confirmed in a study using matched historical controls [112], although this study used lower doses and a greater interval as advised by Rosen [13-15,108,113,114]. Dose intensity and/or serum levels of methotrexate have proved to be of prognostic significance [115-117], although its efficacy as a solitary preoperative treatment was questionable [117]. The first European trial (EOI) comparing cisplatin and adriamycine with this regimen plus high-dose methotrexate did reveal, however, that the disease-free survival was significantly higher in the twodrug arm, although overall survival was not [118]. The role of intra-arterial administration of cisplatin is still under debate [116,119-121].

Prognostic parameters have proved to be the alkaline phosphatase level [122], absolute tumor length of $10 \mathrm{~cm}$ [123] or size of $100 \mathrm{~cm}^{2}$ [121], absolute tumor volume of $150 \mathrm{ml}$ [123], and a good histologic response to chemotherapy in the surgical specimen $[124,125]$. The latter has been confirmed by many other studies.

The role and dose intensity of adriamycine seems to be important $[116,126,127]$. The addition of ifosfamide to schemes consisting of adriamycine and high-dose methotrexate with or without cisplatin has proven to be effective, especially with regard to histopathologic response [128]. However, the combination with ifosfamide has its drawbacks because of its potential for adding to the nefrotoxicity of cisplatin $[121,129]$. Therefore, the value of dose intensity of the cisplatin-adriamycine scheme is currently being studied in the EOI. The value of altering chemotherapy in the postoperative period depending on the histological response to preoperative treatment is currently being investigated by the COSS group.

The role of limb saving surgery in pediatric soft tissue tumor (especially rhabdomyosarcoma) extremity lesions is limited. Rhabdomyosarcoma extremity lesions are most frequently of alveolar subtype, occur in older children, and have a relatively bad prognosis. In most cases and studies diagnostic biopsy is followed by initial chemotherapy consisting of vincristine, actinomycine D and ifosfamide (VAI or IVA) [130,131] or this combination with adriamycine (VAIA) [132]. Primary, mutilative surgery is not customary in most studies and most frequently incomplete response to chemotherapy is followed by radiotherapy [130-132]. However, the role of limb saving or more extensive secondary surgery should be reappraised, because verification by biopsy of complete clinical remission in cases not receiving radiotherapy could not prevent a high number of local relapses [133].

The efficacy of adjuvant chemotherapy in the treatment of soft tissue tumors of the extremities in adults is 
doubtful, especially with regard to prolonged survival $[134,135]$. Ifosfamide and adriamycine appear to be the most active drugs with response rates of $24 \%[136,137]$. Another drug with modest activity is dacarbazine (DTIC) with a response rate of about $17 \%[138,139]$, almost exclusively used in combination chemotherapy. Promising results have been reported on the treatment of (recurrent) soft tissue sarcomas in the extremities by isolated perfusion of the limb with melphalan, tumor necrosis factor and interferon gamma [140,141]. A further development, not necessarily restricted to soft tissue sarcomas in the extremity, may be intra-arterial infusion with cisplatin.

\subsubsection{Radiation therapy}

3.3.2.1. Radiation therapy of bone tumors. Techniques and treatment volume. Radiation therapy of malignant bone tumors requires meticulous planning. Exact knowledge of tumor localization, of macroscopic tumor extent and of all tissues at risk of microscopic disease is essential to define the clinical target volume. This information is obtained by clinical examination, MRI and, if available, the resected specimen. The design of a reproducible and comfortable patient set-up with the aid of immobilization devices such as vacuum pillows and casts, is necessary.

Decisions have to be made about the choice of radiation technique (external beam, intraoperative therapy or brachytherapy), radiation beams and beam modifiers (wedge filters, compensators). A CT scan at the therapy stage can be helpful in determining the choice of radiation beams.

In the first phase of treatment the clinical target volume consists of macroscopic tumor and a margin for microscopic disease. If the medullary cavity of the bone is involved, the radiation volume includes the whole bone, with attention to the epiphysis in young children. The epiphysis distal to the tumor may be spared if a 5$\mathrm{cm}$ margin can be assured. In the second phase of treatment a boost of radiation is given to the area of macroscopic disease. In extremities a strip of tissue should be spared to keep the lymphatic system functioning.

Ewing's sarcoma. Radiation therapy has played the major role in obtaining local control in Ewing's sarcoma. However, since the successful adoption of chemotherapy with increasing evidence of it prolonging disease-free survival, the still relatively high rate of local failure following radiation therapy has become evident $[142,143]$. In view of the increased risk of local failure with increasing size of the primary tumor, a large bulky tumor should be considered a relative contraindication to radiation therapy alone to obtain local control $[99,144,145]$.

Analysis of patients in the Intergroup Ewing's Sarcoma Study and in other clinical investigations did show that the tumor volume is prognostically important [146]. The current treatment protocols for Ewing's sarcoma often begin with 3-5 cycles of induction chemotherapy. After that, depending on tumor response, the local treatment consists of surgery combined with irradiation or radiation therapy alone. Initial results of the Pediatric Oncology Group study showed no advantage for wholebone irradiation compared with tailored portal irradiation [147].

In 1992 the European Intergroup Ewing's Sarcoma Study initiated a phase III study. In this multicenter trial, among other things, the impact of surgery and two types of radiation therapy on local control, overall survival and morbidity will be evaluated after 4 courses of induction chemotherapy. Radiation therapy is given in conventional daily fractions or as hyperfractionated accelerated split course radiation.

The indications for postsurgical radiation therapy and the recommended doses depend on the Enneking classification of the surgical intervention and the histological response of tumor following chemotherapy. These indications are intralesional surgery ( $55 \mathrm{~Gy}$ ), and marginal surgery with a poor response to chemotherapy (55 Gy), marginal surgery with a good reponse (45 Gy), and wide resection with a poor response $(45 \mathrm{~Gy})$. After a wide resection and a good response to chemotherapy and after radical surgery radiation therapy is not recommended.

For patients with an early local or multifocal recurrence or multifocal disease at diagnosis, investigations with respect to the use of autogenous or allogeneic bone marrow transplantations after myelo-ablative radiochemotherapy are in progress (NCI, CESS).

Osteosarcoma. At present the best standard treatment for osteosarcoma is the combination of systemic chemotherapy and surgical resection [148-150].

Radiation therapy is only applied for patients requiring palliation for advanced, inoperable tumors of extremities, pelvis and axial sites.

The palliative radiation dose has to be up to $70-80$ Gy in 7-8 weeks at 10 Gy each week, but this dose has to be adapted to the tolerance dose of surrounding normal tissues.

A possible novel approach is the combination of highdose-per-fraction irradiation with intra-arterial 5bromodeoxyuridine as a radiosensitizer, and simultaneous infusions of methotrexate-leucovorin. This scheme has resulted in high normal tissue toxicity [151].

Other investigators used high-dose radiation therapy together with intravenous iododeoxyuridine or misonidazole as radiosensitizer and chemotherapy resulting in $75 \%$ local control [152]. New fractionation schemes and radiosensitizing drugs, or both, should be considered.

3.3.2.2. Radiation therapy of soft tissue sarcomas. Local control can be achieved by radiation therapy 
alone, but it requires extremely high doses of radiation and leads to a high risk of side-effects [153,154]. In several studies it was also shown that the local control rates achieved with radiation alone were inferior to those obtained with surgery and that local control was dependent primarily on the volume of the local tumor [155].

For these reasons, radiation therapy alone in the management of soft tissue tumors is a second choice for primary curative treatment and is mostly reserved for palliative treatment. It is limited to patients who have locally advanced, inoperable, recurrent, or metastatic disease, and patients who refuse surgery.

The main indication for radiation therapy is as adjuvant therapy to surgery. The rationale for this combination is to restrict surgery and add moderate-dose radiation in order to preserve cosmesis, anatomy and function of the extremity involved. Surgery removes the bulk of the tumor and radiation therapy is used to inactivate microscopic disease involving the surrounding tissues.

3.3.2.3. Radiation techniques. As standard procedure, a shrinking-field technique is applied with two or three phases. In the first phase of radiation treatment, the whole anatomic compartment is treated using large fields. This requires often complex treatment planning, field adaptations by individual blocks, and the use of wedge filters and tissue compensators.

Adequate beam configurations have to be determined to avoid irradiation of uninvolved muscle compartments and bone. In extremities a strip of tissue should be spared to keep the lymphatic system functioning. The radiation dose is $50 \mathrm{~Gy}$, given in daily fractions of 1.8-2 Gy, five times per week, with all portals treated every fraction.

In the second phase, the clinical target volume is reduced to the original tumor bed with $2-\mathrm{cm}$ margins, and an additional $10 \mathrm{~Gy}$ is given in daily fractions of $1.8-2 \mathrm{~Gy}$. Often a bolus is used to bring the dose given to the surgical scar up to $60 \mathrm{~Gy}$. If surgery is not radical and macroscopic disease is left, then the third phase follows with an extra tailored fractionated boost dose of $10 \mathrm{~Gy}$.

This standard shrinking field technique concerns external beam irradiations with photons or electrons. In some cases special techniques may be used like proton therapy, intraoperative electron beam [156-158] and interstitial brachytherapy $[159,160]$.

In combined treatment, radiation therapy can be administered preoperatively, intraoperatively or postoperatively.

Preoperative radiation therapy. This technique has several theoretical advantages: (i) the clinical target volume can be limited to the clinically and radiologically demonstrated tumor and the surrounding tissues at risk of microscopic disease because no surgically manipulated tissues are present; (ii) the mass of the tumor after radiation may become smaller by the time of surgery and that may facilitate resection; (iii) inactivation of tumor cells by radiation may decrease the risk of tumor implantation and embolization during surgery; and (iv) an irresectable tumor mass may become respectable after radiation therapy.

Several studies showed that planned preoperative radiation therapy in patients with histological high grade sarcomas can have good results $[17,16,161,162]$.

Intraoperative radiation therapy. Intraoperative radiation therapy is given during surgery mostly as a high single dose of electron beam irradiation to the tumor bed after moving normal tissues out of the radiation field. The electron energy varies from 9 to $18 \mathrm{MeV}$ depending on the required depth of penetration. The dose of 10-20 Gy depends on the anatomical site and on field size. It is usually combined with fractionated external beam therapy. In most studies tumors in the retroperitoneum were involved. The benefit of intraoperative radiation therapy in terms of local control and disease free survival is still not clear, when compared to pre- or postoperative external beam radiation therapy [156-158]. This technique is still under investigation.

Postoperative radiation therapy. In most institutions postoperative radiation therapy is used $[17,163,164]$. The advantages of postoperative radiation compared to preoperative are: (i) complete information regarding the exact extent, localization, histologic grade and resection margins of the tumor is available for determination of the clinical target volume; (ii) decreased risk of wound healing complications; and (iii) no delay of resection.

The presence of the following are indications for postoperative radiation therapy: all histological high grade tumors; all recurrences, even when surgery is radical; spill during surgical intervention; irradical surgery when reexcision is not possible or too mutilating; resection with a margin $<2 \mathrm{~cm}$; and reexcision following incomplete surgery if the whole surgical area is not resected. In principle, the clinical target volume for postoperative radiation therapy includes the original tumor volume, possible subclinical or microscopic extensions and contaminated areas due to surgery, for example the site of drain and haematoma.

This clinical target volume should be defined by physical examination, information obtained from preoperative imaging studies (CT, or preferably, MRI), the extent and method of surgery, size and histological grade of the tumor.

The following guide-lines can be advised:

(i) The clinical target volume for intracompartmental tumors is the whole compartment concerned.

(ii) The margin for extracompartmental high grade tumors in the first phase is $7-10 \mathrm{~cm}$, taking the anatomical boundaries into account. For the extremity, these anatomical boundaries are determined by interosseus 
membranes, major facial planes or bones. For low grade tumors the margin is $5-7 \mathrm{~cm}$. Regional lymph nodes are usually not treated, but such treatment has to be considered in the case of synovial or epitheloid sarcomas.

(iii) In the second phase, the clinical target volume for the boost dose is the volume of the original tumor with a margin of $2 \mathrm{~cm}$.

(iv) After an unradical resection, third phase, the maximum dose is given to the preferably radio-opaque clipped remaining tumor area with a margin of $1 \mathrm{~cm}$.

Interstitial brachytherapy. Interstitial brachytherapy with iridium-192 or iodine- 125 sources can be used in selected cases to boost the tumor bed in combination with external beam therapy $[159,160]$. Plastic tubes are placed at $1-\mathrm{cm}$ intervals surrounding the target volume at the time of surgery and the target area is marked with radio-opaque clips for dosimetric calculations. Temporary implants are employed using after-loading techniques. This mostly has consisted of a single-plane implant. Reduction of the high rate of wound healing complications has been achieved by postponing the loading of radioactive sources until after the fifth postoperative day [160].

\subsubsection{Surgical adjuvant therapy at the time of operation}

3.3.3.1. Cryosurgery. Cryosurgery, the spraying of nitrogen liquid at $-190^{\circ} \mathrm{C}$, may sometimes be indicated in certain cases of malignant bone tumors. The method was developed by Marcove [165] in the early seventies, and was especially advocated for aggressive benign tumors, like giant cell tumor or chondroblastoma. In some low grade malignant tumors, located in sites where wide excisions margins would induce major disability, this method of treatment should be considered. Scientific arguments for these statements are based on studies by Malawer [166]. Examples of this combination are: chordoma of the sacrum and low grade malignant tumors of the vertebral body. In principle the lesion is excised with an intracapsular or marginal margin and in addition liquid nitrogen is poured or sprayed into the resection cavity. As the method respects anatomic lines, it certainly can be part of limb saving surgery. In some rare cases the method is also used as a last resort palliation method, for instance in osteosarcoma of the vertebral column or sacrum, where neither chemotherapy nor radiotherapy could accomplish a reduction of the tumor. In our experience this method has proven its value in special cases as outlined above.

\subsection{Site of the primary tumor}

We will now discuss the actual surgery, where the limb salvage takes place. For the purpose of clarity, this chapter is divided into three sections, covering the upper extremity, the axial skeleton including the vertebral col- umn and the pelvis, and finally the lower extremity. In each section the consequences of excision and resection will be outlined and options for reconstruction will also be mentioned.

\subsubsection{Upper extremity}

All resections should be performed according to the Enneking staging system $[43,44]$, which implies adequate surgical margins in accordance with the biological characteristics of the tumor. If these margins cannot be obtained without compromising the optimal oncologic strategy, an amputation or disarticulation should be performed.

In tumors of the hand, ray excision may be a feasible procedure. Reconstruction is seldom required or possible. In tumors of the wrist [167] local en bloc excision is sometimes possible. Reconstruction in these cases may be accomplished by implantation of an endoprosthesis [168] or even an allograft, in order to give mobility to the joint. However these methods often fail and therefore a more biological reconstruction should be preferred, for instance with the aid of a vascularised fibula [169] or iliac bone transplant. In these cases the reconstruction is identical with an arthrodesis of the wrist.

Due to the closeness of important neurovascular structures, tumors of the forearm and elbow are seldom accessible to limb saving surgery. If an excision or resection with adequate margins is possible, reconstruction may be considered with an allograft or endoprosthesis. From a functional point of view, an arthrodesis for the elbow is not a feasible alternative. Endoprosthetic reconstruction in the area of the elbow joint will in the long term be subject to loosening, and reconstruction with an allograft may be complicated by the development of pseudoarthrosis between the host bone and the graft, infection and fracture.

Many tumors of the upper extremity are located in the humerus, especially the proximal metaphysis and diaphysis. Often resection in this area can be performed with adequate margins. Reconstruction may be accomplished with an endoprosthesis [170], allograft or vascularised fibula (Fig. 1). These methods guarantee a good turning point for the elbow and forearm. However in most cases active shoulder function is restricted due to the amount of soft tissue resection. Because the humerus is not a weight bearing bone, most types of reconstruction, both intercalary, osteoarticular and endoprosthetic survive for a long time. For many years tumors of the scapular region and shoulder joint itself could not be removed without sacrifice of the upper limb. However since Tikhoff and Linberg [171] described the procedure which was named after them, and since the further development of this procedure by Malawer [172], tumors in this region are often amenable to limb saving surgery. After partial resection of the scapula and the proximal humerus, a flail upper arm is prevented by 

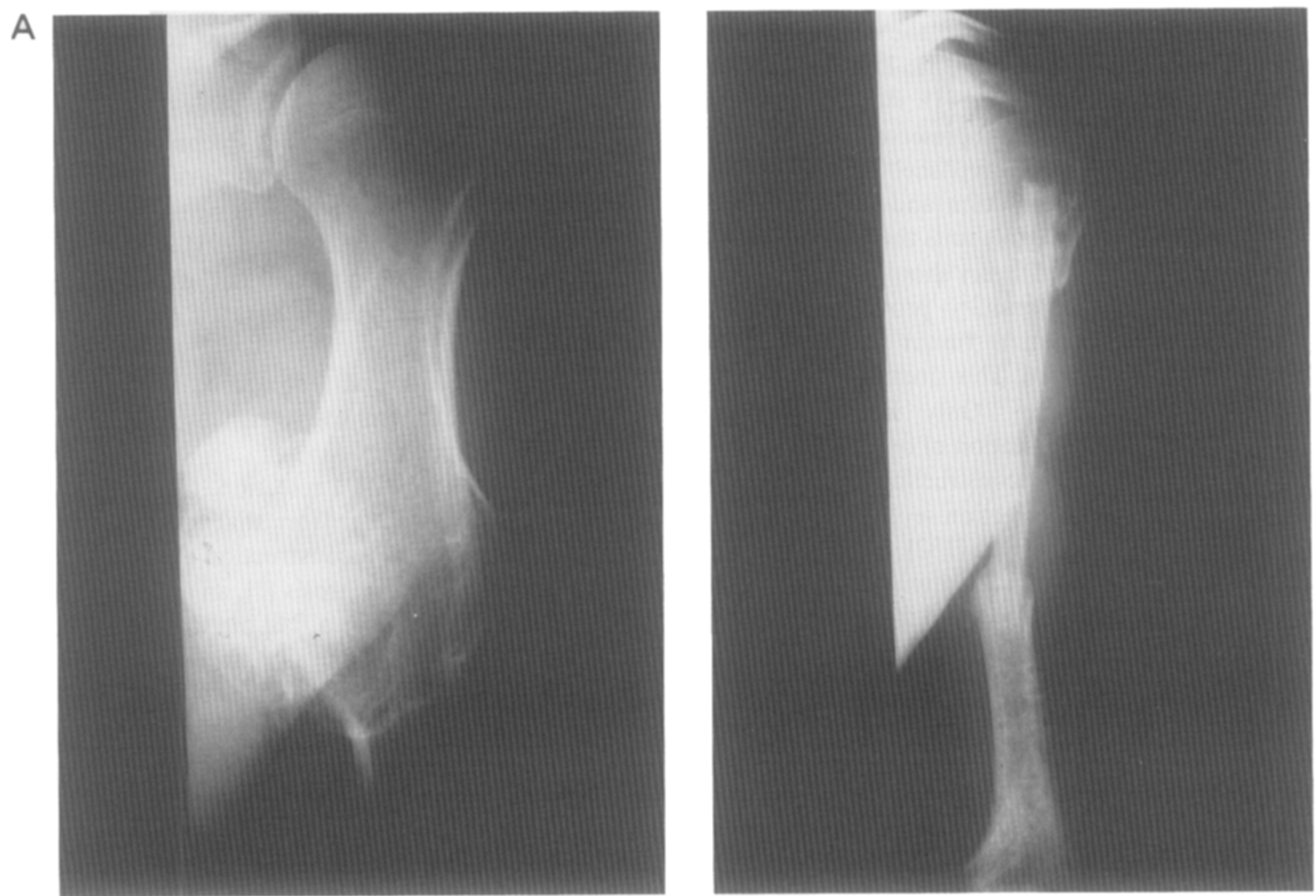

Fig. 1. (a) $I^{B}$ chondrosarcoma of the proximal humerus. (b) Same patient, after incorporation of the graft.

reconstruction with an endoprosthesis or allograft which is fixed between the remnants of the scapula and the humerus. Although normal shoulder function is never obtained, the cosmetic result of the shoulder is good as well as the functional results of the elbow, forearm and hand.

Sometimes even the whole scapula is removed in this procedure. A Kintscher rod may then provide for the bridging of the defect between the humeral diaphysis and the thoracic wall. Complete resections of the scapula have been reconstructed by implantation of an endoprosthesis. These reconstructions are still experimental and should not be regarded as common limb saving practice, although the results, according to Eckardt [173], are promising.

\subsubsection{Axial skeleton}

3.4.2.1. Vertebral column. The vertebral column is certainly one of the areas in musculoskeletal oncology where limb salvage is hardly a feasible option, due to the closeness of important neural and vascular structures. Although resection in malignant tumors can sometimes be performed with adequate margins [174,175], this often only pertains for small tumors in this region. In these cases reconstruction may be obtained with allograft bone, spinal instrumentation or even endoprosthetic replacement. However, in our view, after adequate resection, reconstruction in this area should preferably be performed on a mainly biological base, for instance with autogenous vascularized bone and spinal instrumentation. A biological reconstruction will reduce the risk of complications in the long term and this is an important feature especially in the spinal region. All secondary operations will again endanger vital structures of the spinal canal and its surroundings.

3.4.2.2. Pelvis and sacrum. In the field of limb salvage, tumors of the pelvis and sacral areas are the most challenging [176]. The main reason for pursuing limb salvage in these areas [177], is the fact that hemipelvectomy and sacrectomy are mutilating procedures, both somatically and psychologically. Due to the usually large size of these tumors [178], large resections of bone and soft tissue are often necessary in order to obtain adequate surgical margins. This is the main reason why limb salvage in these areas often does not yield an acceptable functional result [179].

Critical structures which should not be involved or contaminated in order to preclude limb salvage are: the sciatic and femoral nerve, the iliac and femoral vessels and a major portion of the gluteal muscles and the surrounding soft tissues.

According to Enneking [180], three types of resection 
may be distinguished with respect to the pelvis: I. Iliac (IA: including the gluteal muscles); II. Peri-acetabular (IIA: including the hip joint); and III. Ischiopubic.

In type I resection the hip joint is preserved and restoration of the pelvic ring can be accomplished by bone grafts interpositioned between the sacrum and the iliac remnants. A vascularized fibula graft suits this purpose well [181]. Allografts or endoprostheses should not be used. In most cases of type II resection - provided that one has to deal with a malignant tumor - the entire acetabulum has to be resected. This situation presents a challenge for reconstruction. Only in the almost hypothetical situation that resection of only one third of the acetabulum is required, is reconstruction not necessary [178]. After peri-acetabular resection several options are available regarding reconstruction [182]. An iliofemoral arthrodesis [176,179,183] (Fig. 2) often ends up in a pseudoarthrosis, and the iliofemoral pseudoarthrosis should be compared functionally to a flail hip. An ischiofemoral arthrodesis often takes the same track [184] and as a result most patients who undergo either an iliofemoral or an ischiofemoral arthrodesis end up with a leg length discrepancy, use one or two crutches and lack stability of the hip joint. A successful arthrodesis may be accomplished in $42 \%$ of the patients [176].

Alternatives are the use of an allograft, an endoprosthesis or a composite of both [183].

The results of reconstruction with an allograft are confusing $[179,185,186]$. Some authors mention good results, others stress the risks of non-union, hampering the process of revitalisation, and finally conclude that allograft reconstruction should still be regarded as experimental [179,185-187]. Late fractures and the occurrence of a Charcot joint are important features, in addition to degenerative changes in a transplanted hip joint.

An endoprosthesis could be chosen as a reasonable alternative. The options are a pelvic prosthesis (Fig. $3 a-c)$, including a hip joint $[182,188,189]$, or a saddle prosthesis $[190,191]$ (Fig. 3d). Although the restoration of the pelvic ring is often accomplished by a pelvic prosthesis, the results of this type of reconstruction are often poor, due to the soft tissue deficiency or the occurrence of loosing, with or without infection. This also applies for the composites, which consist of a pelvic allograft and a prosthetic total hip replacement.

The saddle prosthesis may yield a smaller risk of complications. After its introduction in 1982, it has been used in increasing numbers with success world-wide.

In all types of peri-acetabular reconstruction general complications are to be expected: infections, skin necrosis, neurovascular lesions and large haematoma $[176,178,184,192,193]$. The more complex the method of reconstruction, the greater the risk of complications. The frequency of these complications varies from 20 to $65 \%$.

Type III resections generally do not require reconstructions [178]. The pelvic ring may be interrupted, but this does not impose extraordinary stress forces on the hip or sacroiliac joint.

A combined I-II-III resection however presents a major challenge for reconstruction. Reconstruction in this situation requires the utmost ingenuity of the surgeon and engineer. A sacrofemoral fusion with the aid of a vascularized graft may be chosen [193], but, after a long period of immobilisation the patient often ends up with a leg length discrepancy and the graft is also at major risk of fracture.

A hemipelvic allograft, combined with a hip endoprosthesis, is an alternative with many risks, as has been mentioned before [193].

After a combined II-III resection, the reconstruction essentially does not differ from that following a type II resection. Methods of reconstruction are an iliofemoral arthrodesis or pseudoarthrosis [7], an allograft or a saddle prosthesis [194]. Even a flail hip may be acceptable.

After a combined I-II resection, reconstruction may be performed by a fusion between the ischium and the femur or between the ischium and the sacrum with the aid of the partially transposed ipsilateral proximal femur. An endoprosthesis consisting of a custom-made acetabulum bearer and a proximal femur prosthesis could provide for mobility and restoration of the junction between the remaining part of the ipsilateral femur and the reconstructed hemipelvis [194]. This method of reconstruction is still experimental and has a high risk of complications.

Resections of the sacrum are almost inevitably linked to neurological deficits and loss of stability [195-197]. According to Enneking, wide margins may be achieved during resection of the entire sacrum with 'acceptable' deficits, but radical margins will often result in a hemicorporectomy. A wide resection is often associated with the occurrence of incontinence, paraplegia and impotence.

Reconstructions in these cases are experimental; their main purpose is to refixate the iliac bone to the vertebral column [198].

Seldom can a unilateral sacral resection of a tumor be achieved with wide margins. Due to the presence of the remaining contralateral sacrum, the neurological deficits may be less important.

\subsubsection{Lower extremity}

The thigh, the upper part of the leg and the distal part of the femur, are the parts of the body where limb saving surgery was attempted for the first time [3,5]. Due to the fact that tumors in these areas often manifest in an early phase and that an abundant amount of soft tissue is usually present, limb salvage often succeeds with a good result both oncologically and functionally. Limb salvage was first attempted in the area of the thigh (Fig. 4), but nowadays complete resections of the femur, hip and knee joint, as well as combined distal femur and knee resections (Fig. 5), are common practice in this field of surgery. Of course the rules, which were outlined above (Section 
A

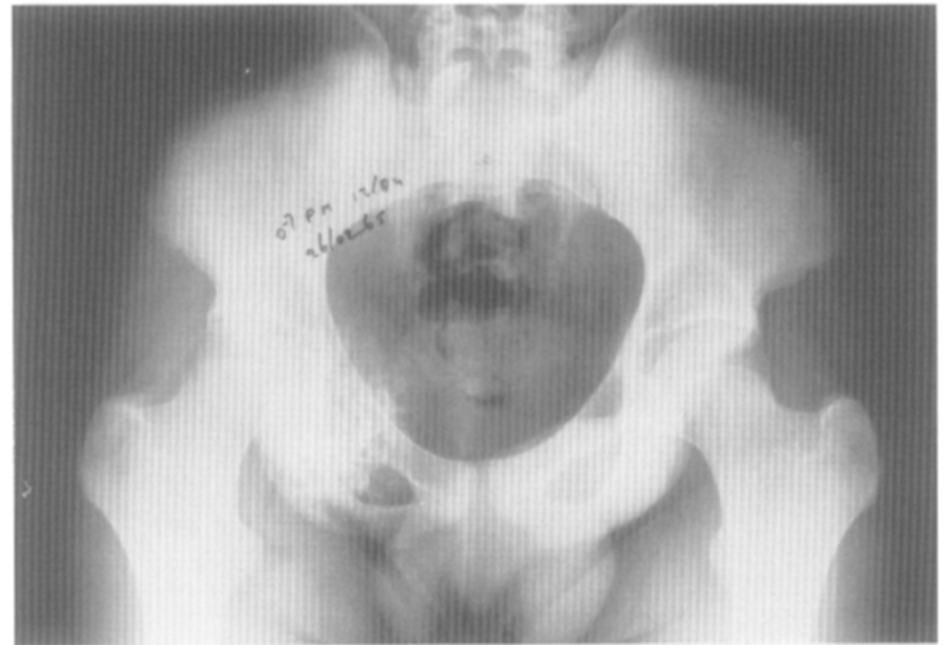

B

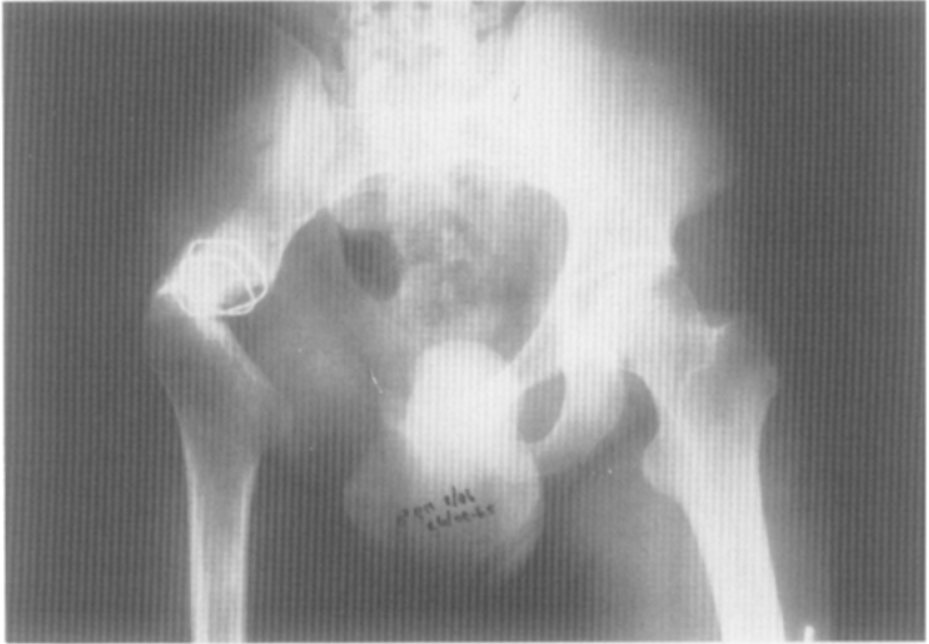

$\mathrm{C}$

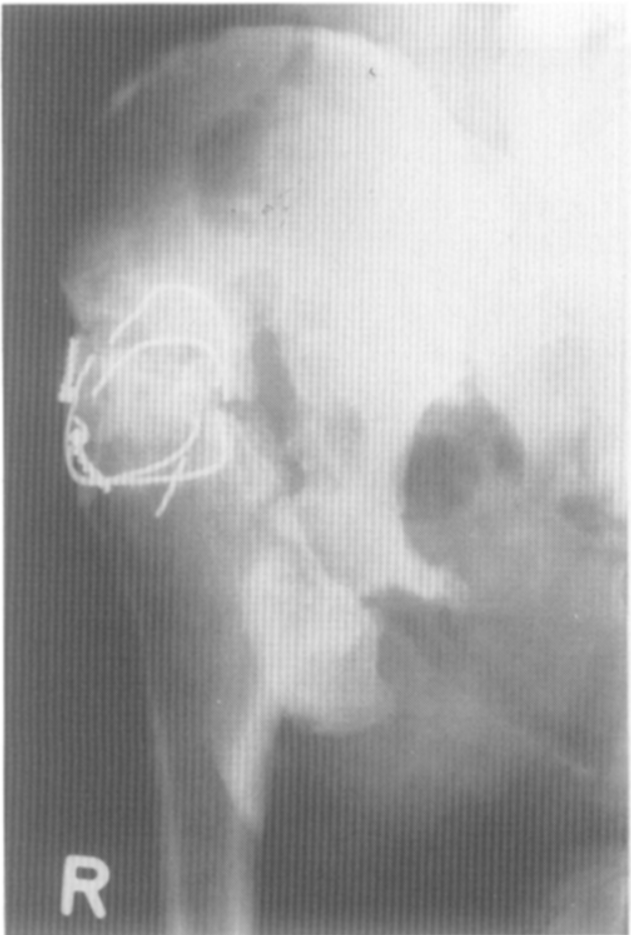

Fig. 2. (a) $I^{B}$ chondrosarcoma of the periacetabular region. (b) At tempted iliofemoral arthrodesis after wide resection. (c) Iliofemoral pseudarthrosis after failed arthrodesis. 
$\infty$
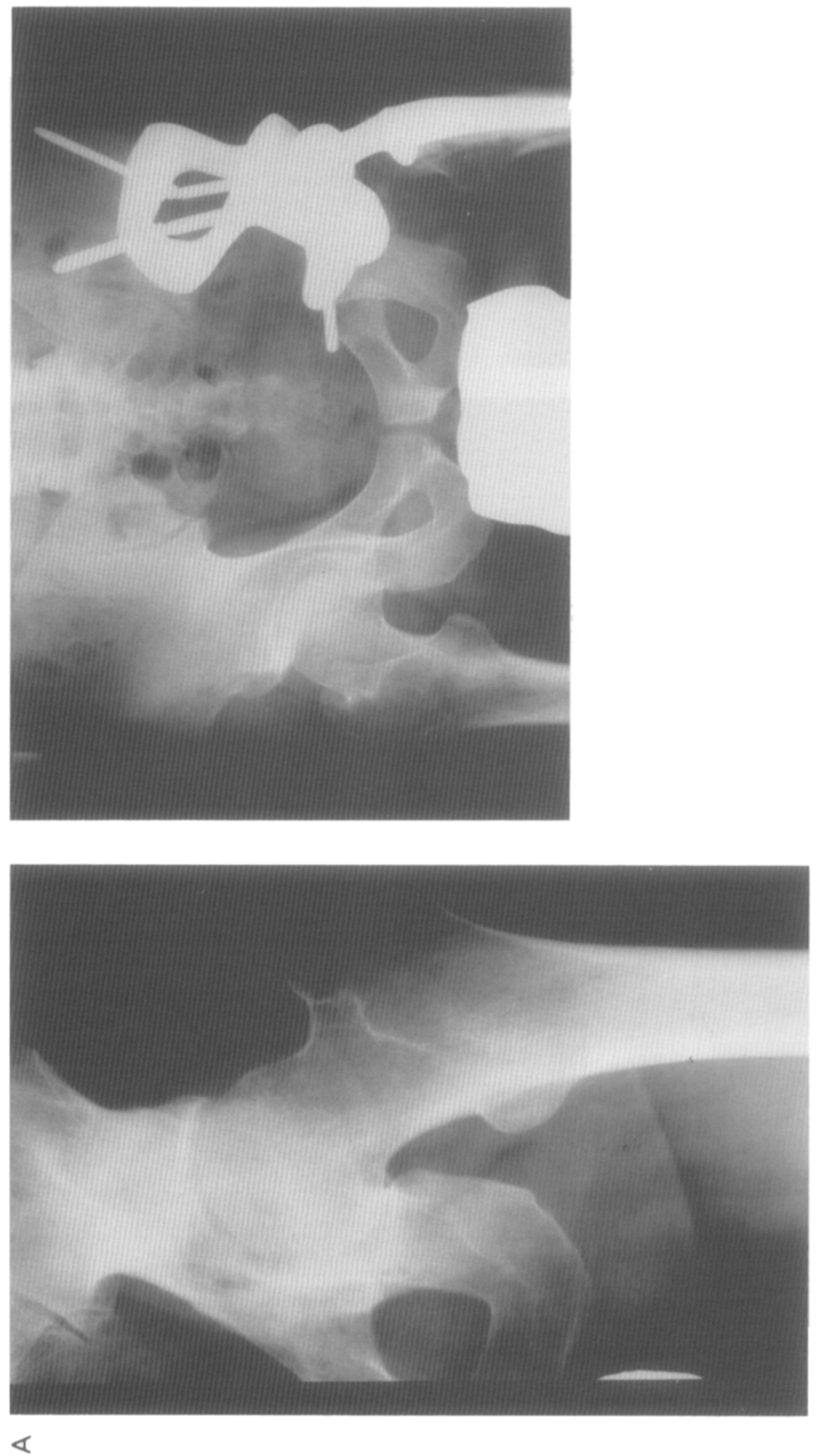
○
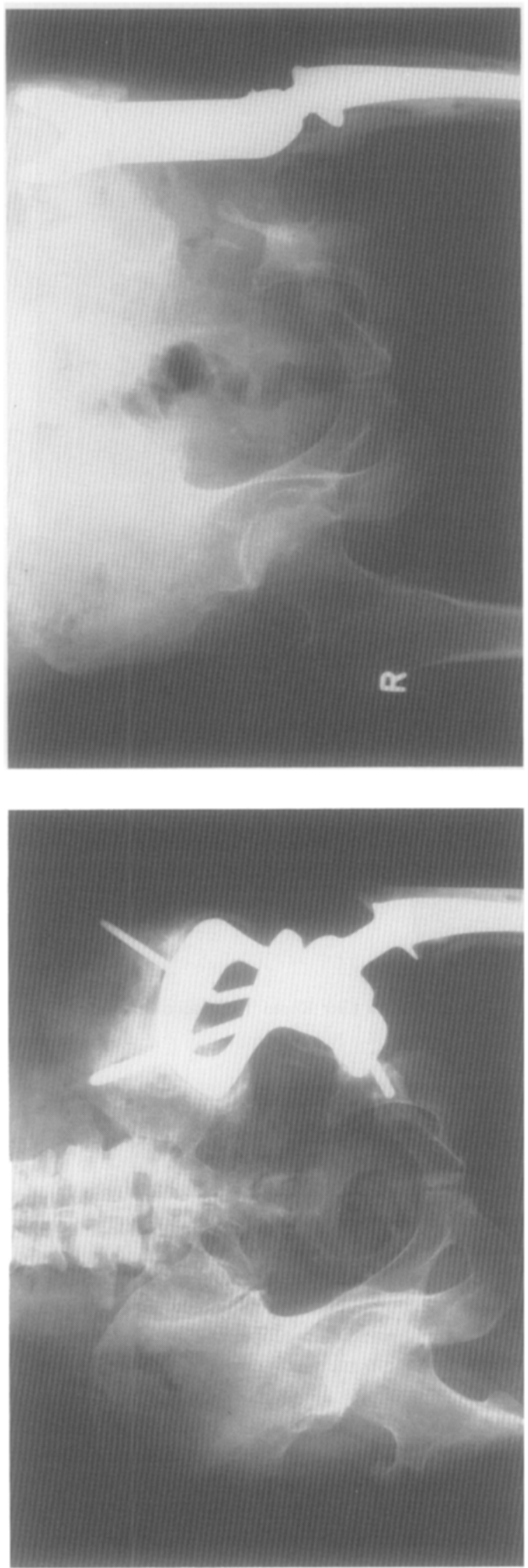

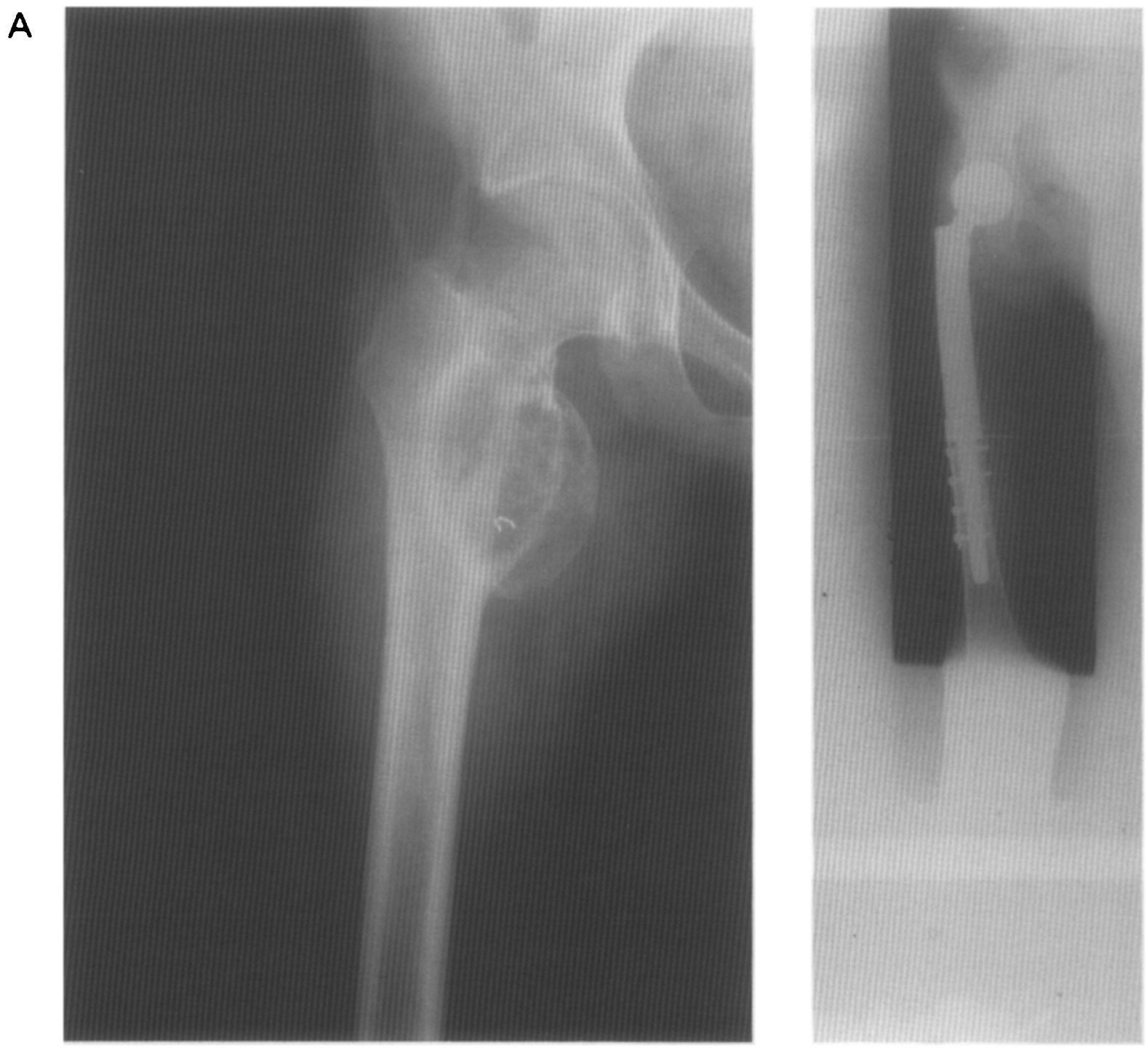

Fig. 4. (a) $\mathrm{Il}^{\mathrm{B}}$ osteosarcoma of the proximal femur, with secondary ABC. (b) Reconstruction after Rosen $\mathrm{T}_{7}$ protocol and marginal uncontaminated resection with proximal femur/hip prosthesis after 10 years.

2), must be taken into account, but this can easily be done. Reconstructions can either be performed with allograft bone or mega-endoprosthetic replacements $[168,170]$ or with vascularized bone grafts $[169,199,200]$. In general the surgeon will pursue active mobility of the artificial joint, but under special circumstances, especially in the area of the knee, a resection arthrodesis may be the best solution. As an alternative to allograft or endoprosthetic reconstruction intercalary diaphyseal reconstruction may be performed with a combination of autogenous bone and a Küntscher rod (Fig. 6).

Either vascularized or non-vascularized fibula bone or tibial chips can be used in this respect. In children reconstruction with an allograft or conventional megaendoprosthesis will eventually result in a leg length discrepancey. This complication can be prevened by the use of an invasive [201-203] or non-invasive [204-206] adjustable lengthening prosthesis.

Fixation of the implants or grafts can be achieved in different ways. Mega-endoprostheses may be fixed with or without cement. Essentially the debate concerning the choice does not differ from the one which is still going on with respect to ordinary artificial joints, like total hip and knee replacements. Allografts may be fixed with plates and screws or with an intramedullary nail. In Section 5 we will detail the advantages and disadvantages of both methods. Leaving aside the assumption that an allograft will revitalise completely, the discussion concerning the fixation methods refers to the way in which incorporation of the allograft occurs. Those who believe in an endosteal pathway most probably will use a plate and screws, and those who choose a periosteal pathway will use an intramedullary nail.

Both endoprosthetic and allograft reconstruction will eventually lead, after either a few or many years, to complications, a situtation the surgeon has to deal with $[194,207]$. These problems will be outlined in Section 5 .

Due to its lack of soft tissues the upper part of the lower 

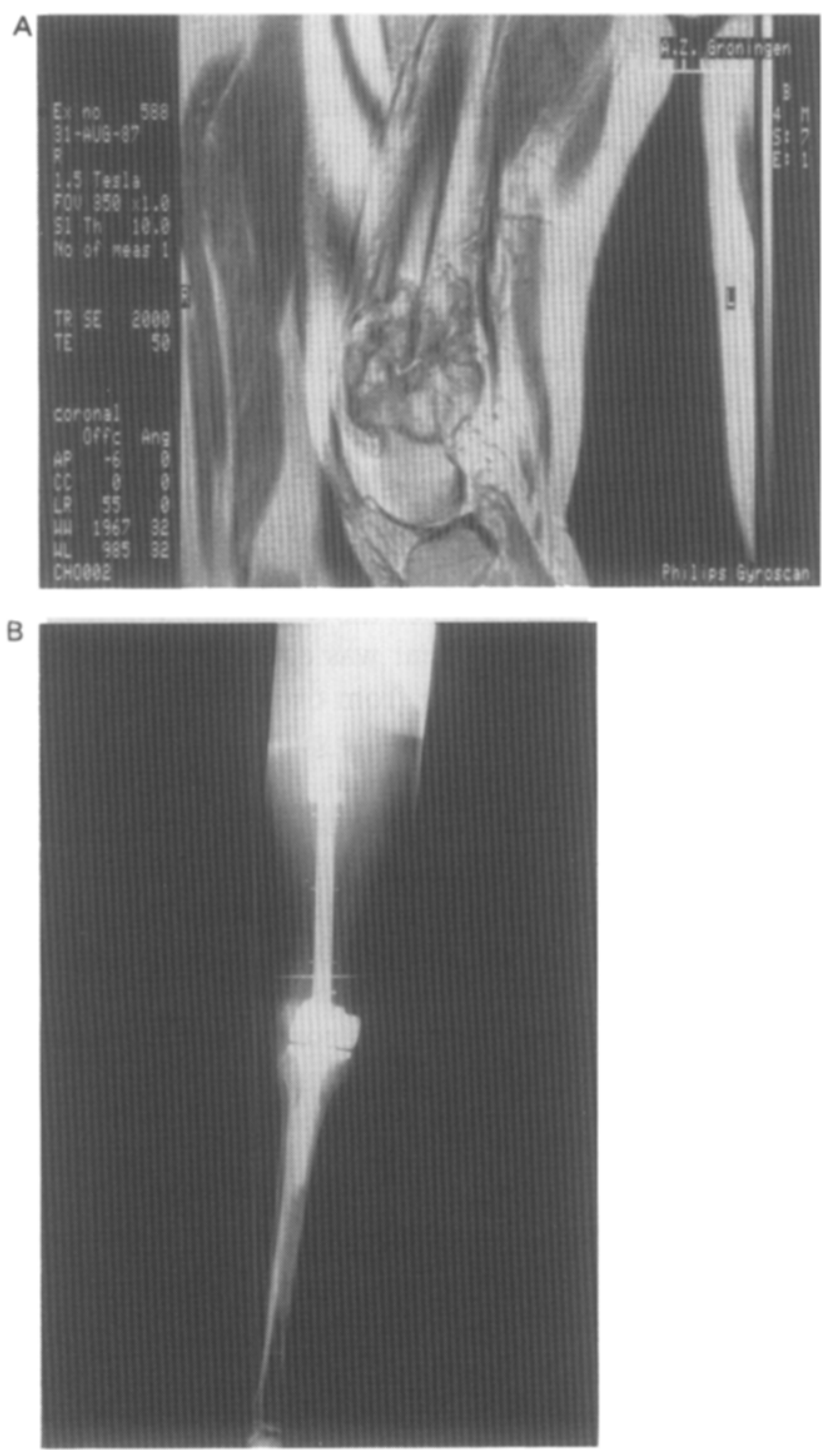

Fig. 5. (a) MRI of II $^{\mathrm{B}}$ osteosarcoma of the distal femur, with pathological fracture. (b) Reconstruction with distal femur/knee endoprosthesis after Rosen $T_{10}$ protocol; $>90 \%$ necrosis, wide resection.

leg is difficult to reconstruct. Tumors in this area are rather frequently amenable to limb saving surgery. However, due to the anatomical circumstances, the main neurovascular bundle is more frequently compromised than for instance in the distal part of the upper leg. If resection of a tumor in the proximal part of the lower leg is possible, reconstruction presents two important challenges [208]. First, the refixation of the patellar tendon in order to restore active function to the quadriceps, and second, the coverage with soft tissue of the reconstructed area at the ventral side. This especially holds true for reconstructions which enable active mobility of the knee joint. Usually a resection of a tumor of the proximal part of the lower leg includes the knee joint. In endoprosthetic replacements the megaprosthesis will include a diaphyseal-metaphyseal replacement and an ar-
A

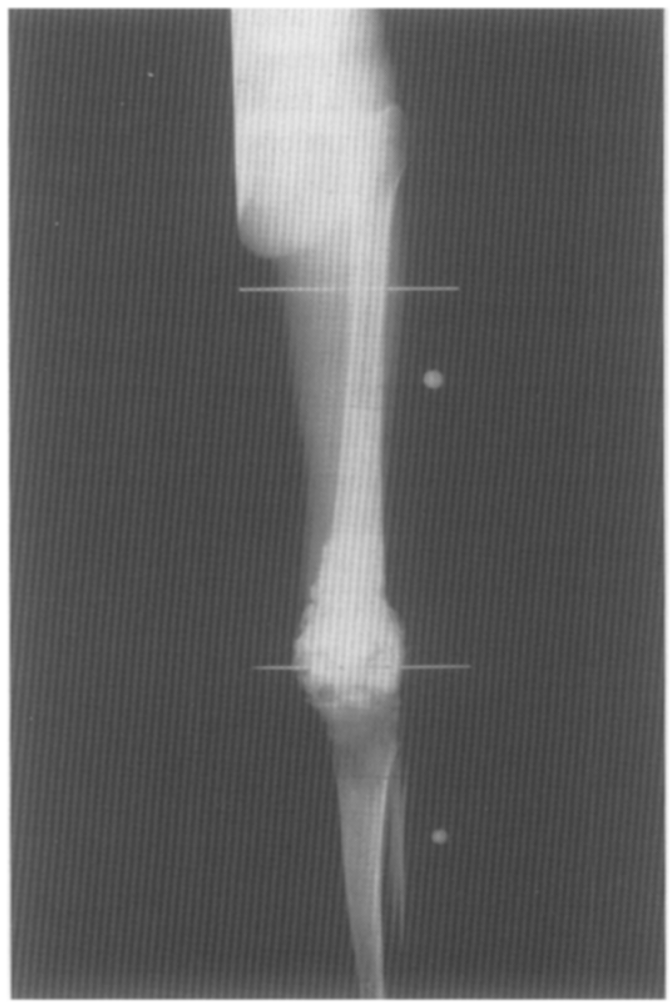

B

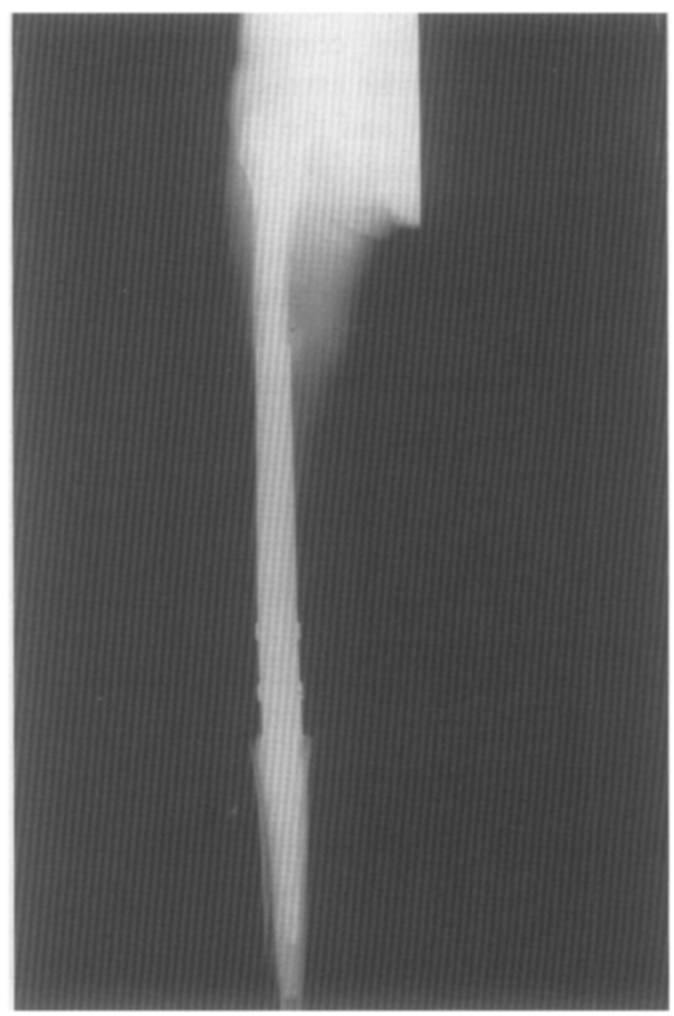

Fig. 6. (a) II ${ }^{\mathrm{D}}$ osteosarcoma of the distal femur, with involvement of the knee. (b) Wide extra-articular resection after chemotherapy, followed by arthrodesis with implant.

tificial knee joint. In the early years of limb salvage, allograft reconstructions were performed which replaced the resected area, but the reconstructions resulted in many complications, such as fractures of the bone, 
osteoarticular dysfunction and insufficiency of the ligaments. Therefore, this type of reconstruction should no longer be regarded as a feasible option.

At present most reconstructions are performed with the aid of an endoprosthesis [208] or a composite consisting of an endoprosthesis and an allograft [209]. Advocates of the latter arrangement claim that the patellar tendon can be fixed more easily to the allograft tibial replacement, which is fixed to the endoprosthesis by the intramedullary stem of the prosthesis. But this type of reconstruction meets the same soft tissue deficits as the reconstruction with a mega-endoprosthesis alone. The major step forward in dealing with this problem was proposed by Malawer [210] who advocated the use of the medial head of the gastrocnemeus muscle, leaving its vascular bundle intact.

The transposed muscle covers the upper anterior part of the reconstructed area and thus provides for adequate soft tissue coverage. The patellar tendon can easily be sutured to the transposed muscle, thus creating a biological part of the whole reconstruction. Other methods have been described for this purpose [211], but to our knowledge the gastrocnemeous transposition serves the goal in the best way.

We would like to emphasize that all tumors that have, or most probably have, contaminated the knee joint should be treated with an extra-articular resection. This means that the tumor and the knee joint is resected en bloc with adequate margins. Inadequate margins will often result in local recurrence and this should be avoided in all circumstances. An extra-articular resection could be reconstructed with a resection arthrodesis as has been mentioned above.

Sometimes resections and excisions in the area of the knee joint include the removal of essential parts of the extensor mechanism. In order to restore the strength of the extensor mechanism transposition of flexors has been performed, e.g., the biceps femoris or semitendinosis. As the strength of transposed muscle diminishes by $30 \%$ and as the operation field has to be extended - which might increase the risk of infection - a transposition should only be performed after thorough consideration. One should keep in mind that the effect of muscle transposition is still under discussion with regard to expected enhancement of muscle strength [212].

The lower leg, ankle joint and foot are hardly ever subject to limb saving surgery. Adequate margins around tumors in these areas preclude feasible bony or prosthetic replacements and fixation, and also the lack of soft tissues make coverage almost impossible. One exception is perhaps when there is a small low grade tumor in the vicinity of the ankle joint, where an arthrodesis might serve as an acceptable method of reconstruction.

\section{Results of limb saving surgery}

The results of limb salvage should be judged both on an oncological base and on the functional outcome. As outlined in Sections 1.5 and 2, the oncological goal of limb salvage should be the complete cure of the patient. The functional goal is to restore the integrity of the part of the body which is involved in an optimal way.

\subsection{Oncological results}

From the very beginning the tumors considered to be amenable to limb saving surgery were osteosarcomas and chondrosarcomas. Much debate has concerned the dilemma of whether limb salvage was equivalent to amputative surgery from an oncologic point of view. In 1984 a consensus meeting [213] was held at the National Institute of Health (USA), during which the conclusion was reached that limb saving treatment was equal to amputative surgery in patients suffering from osteosarcoma or soft tissue sarcomas, provided that the guidelines as outlined in Section 2 were taken into account. At present this statement also applies to other tumors like chondrosarcoma, Ewing's sarcoma, malignant fibrous histiocytoma, adamantinoma of long bones, synoviosarcoma, etc.

Seventy percent of the patients suffering from a malignant bone or soft tissue sarcoma can nowadays be treated with limb saving surgery without compromising the oncologic result $[106,168,170,214]$. For osteosarcoma this includes a five-year survival rate of $60 \%$ and for Ewing's sarcoma the figure is almost similar. It should be stressed however that these figures reflect the average presentation of the tumors. Pelvic and sacral tumors certainly have a worse prognosis compared to tumors of the proximal or distal femur. This is due to the fact that at the time of detection most tumors of the pelvis have extended so deeply into the surrounding tissues that adequate surgical margins cannot be achieved. With respect to Ewing's sarcoma, it should be emphasized that a relationship seems to exist between the overall survival rate and the volume of the tumor; a tumor smaller than $100 \mathrm{~cm}^{3}$ would correlate with a more favorable prognosis.

\subsection{Functional results}

The need for uniform guidelines for functional evaluation of limb saving surgery was expressed by Eckhardt, Sim and Enneking at the first international symposium on limb salvage in Rochester, USA in 1981. Enneking presented the first draft of the guidelines at the second symposium in Vienna, 1983. The system, adapted in the following years, was adopted by the Musculoskeletal Tumor Society (MSTS), and was published in 1993 by Enneking, Dunham, Gebhardt, Malawer and Pritchard [46]. The combination of authors not only suggests a wide support within the USA, but the adoption by the MSTS urges all institutes around the world performing limb salvage to use it $[168,170,207,215]$.

In brief the system assigns numerical values $(0-5)$ to 6 categories; pain, functional emotional acceptance for 
either extremity; support and walking ability plus gait being specific for the lower extremity, and finally hand positioning plus lifting ability being specific for the upper extremity. As results must be presented world-wide in a comparable way, all limb saving institutes should use this system. The authors feel that a survey of functional results which can be expected or achieved in certain areas is not possible. Not only the site of the tumor is important; its extension is especially important, and this varies from tumor to tumor. In general one could say that the best results are obtained in the areas of the hip and knee joint followed by the shoulder and proximal tibia. Pelvic and sacral tumors will obviously close the list.

\section{Complications of treatment}

\subsection{Surgical complications}

In medicine and surgery almost all advanced new techniques result in complications. Limb saving surgery is not an exception [214]. The magnitude of the complications is related to the site and the extension of the surgery, the overall and local conditions of the patient and the impact of adjuvant therapy. The surgical complication with the greatest impact is local recurrence. Local relapse of a tumor should be avoided in all circumstances. As long as the surgeon sticks to the rules of the Enneking staging system, the risk of a local recurrence is small, perhaps about 5\% [216]. The danger of limb salvage is that the surgeon gives more attention to the reconstruction than to the oncologic resection.

One should not compromise oncological margins in order to preserve sufficient tissue suitable for reconstruction, as this will obviously enhance the risk of local recurrence. Unfortunately this attitude was taken by many limb saving institutes in the late 1980s [187,217], and as a consequence the local recurrence figures rose world-wide to $10-14 \%$. In this respect it should be mentioned that the risk of local recurrence after pelvic surgery rose to $50 \%$ $[176,184]$.

If an adequate resection of a tumor can be accomplished just by removal of bone and/or joints, the presence of a sufficient amount of soft tissues will reduce the risk of complication after reconstruction. This is especially true in the region of the pelvis and the proximal tibia. A deticiency of soft tissues calls for additional more or less plastic reconstructive surgery and although this may solve the deficiency, it enlarges the operation and increases the risks of complications.

Large implants, allograft, composites or vascularised autografts for reconstruction do not inevitably lead to an increased risk of complications, provided that the amount of soft tissues left after resection is sufficient. Under these conditions however there is a rule that says: the more extensive the reconstruction, the more hazardous the future.

Complications related to surgery are: haematoma, skin necrosis, neurovascular damage, infection, seroma, thrombo-embolism, urinary infection, etc. The risk of these complications can be reduced by taking the proper precautions pre-, peri, and postoperatively.

\subsection{Complications related to implants or grafts}

\subsubsection{Implants}

All implants are subject to the response of nature to the implantation of a foreign object. In orthopaedic surgery this inevitably results in stress shielding, cement disease, reaction to polyethylene debris and finally loosening [218]. Loosening may be concomitant with infections [183]. Whether this loosening is related to the technique of fixation of the implant is not of special concern to the field of limb salvage. Probably the same arguments for either type of fixation - cemented or non-cemented are valid, compared to conventional joint replacement. However, one of the typical 'limb salvage factors' that act in favour of long-term fixation to bone is the quality of the bone. Most of the patients are young and the good quality of their bone may be of benefit to the durability of the type of fixation which is used.

All implants are subject to wear [183,235]. This may raise technical problems which may require revision surgery. In addition breakage of an implant may also call for revision surgery. Many implants consist of an artificial joint and a replacing segment. Many complications related to wear of the implant obviously occur in the artificial joint. In order to make revision surgery easier a modular type of prosthesis was developed. This enables the surgeon to replace the damaged part without disturbing the fixation of the segmental part to the bone. It should be kept in mind that all orthopaedic implants are more subject to wear and loosening with complications as a consequence, if they are loaded too highly by too much activity by the patient. An average level of activity without participation of the patient in vigorous sports will at least enable a prostheses to survive for 15 years in situ, provided that no other risk factors are present.

\subsubsection{Grafts}

5.2.2.1. Autografts. Autografts encompass the most biological method of reconstruction. If applied vascularized they heal quite easily and quickly. But even unvascularised they are in this respect superior to homogeneous bone. There are two drawbacks. Autogenous bone must be harvested elsewhere in the body of the patient and this will almost always result in additional scars.

The second drawback is the risk of fracture, especially in the first 6-9 months after the operation, depending on the state of vascularisation of the graft.

Being synonymous with the most biological method of reconstruction, and thus enabling the reconstruction to act in a natural way, autografts should be used as much as possible. As the availability of autogenous bone is limited and most resections in limb saving surgery result 
in a major defect of the limb involved, most reconstructions can at best consist of an autogenous part combined with an implant or allograft.

5.2.2.2. Allografts. This material has an ideal modulus of elasticity and perfect tensile and compressive strength. Therefore, it is a subject of major interest in limb saving surgery [219]. It is almost impossible to perform allograft surgery without a bone bank. Donor selection, antisepsis, harvesting and packing are important features of such a bank, the first item is especially of concern with respect to HIV. The main problems with allografts are the high rate of infection, the risk of fracture $[220,221]$ and the risk of delayed union or non-union [186].

Although Mankin and coworkers $[222,223]$ have proclaimed that an allograft would unite completely and even revascularise, many authors nowadays question this statement, especially since Enneking [224] made the observation in retrieval allografts that revitalisation occurred only in $20 \%$ of the graft. Allografts may act like semibiological spacers that are subjected to resorption and immunological processes. Since the complication rate with respect to the non-oncologic part of the treatment varies between 25 and $45 \%$, it certainly does not represent uncomplicated surgery.

\subsection{Complications related to chemotherapy}

Especially in cases with pathologic fractures, chemotherapy may be responsible for delayed fracture healing and may necessitate early surgical intervention.

Preoperative chemotherapy may also be associated with delayed wound healing and significant blood loss during surgery despite normal platelet counts and clotting studies.

During radiotherapy a reduced dose of adriamycine and actinomycine $\mathrm{D}$ of approximately $30 \%$ may be necessary in order to prevent drug-irradiation interactions of normal tissues and scar tissue, which could result in radiation therapy breaks, severe recall phenomena and severe late effects.

Most (late) effects of chemotherapy are related to the specific drugs used in the various schemes: hearing loss due to cisplatin [116], nephrotoxicity due to increasing cumulative doses of cisplatin [121], tubular and glomerular nephrotoxicity due to increasing cumulative doses of ifosfamide [131,225,226], and an increased incidence of nephrotoxicity after combination of ifosfamide and cisplatin [129]. Although the toxicity of high-dose methotrexate is generally mild, subclinical (MRI) central nervous system toxicity may be present [117]. Moreover, there is an increasing awareness of the acute and especially late effects of anthracycline therapy given to young people $[116,121,126,227]$.

\subsection{Complications related to radiation therapy}

Complications of radiation therapy are related to frac- tion dose, total dose, irradiated volume, type of tissues involved, extent of surgery and chemotherapy given.

Acute reactions during or shortly after radiation therapy are usually limited to erythema, dry or moist desquamation of the skin in the high-dose volume if the beams are tangent to the skin, for example in patients with proximal thigh tumors. An early complication may be delayed wound healing.

More serious late complications include edema of the distal extremity, fibrosis, contracture, atrophy, impaired growth, secondary fracture, and radiation induced sarcoma. Edema of the distal extremity can be prevented by careful sparing of a strip of normal tissue to secure lymphatic drainage, especially in patients with a proximal located tumor. The development of fibrosis, contracture and atrophy can be decreased by long-term active physical therapy. If radiation treatment of the pelvis is required, moving the small bowel out of the pelvis should be considered, and in young women transposition the ovarium should be considered.

\subsection{Psychological complications}

The quality of life in bone tumor patients is affected [228] both by limb saving methods as well as by amputation. Compared to the purely mechanical aspects of local motion, the psychological and social aspects of adjustments are more difficult to quantify. According to the literature [229] self-report questionnaires and semistructured interviews have shown that psychoneurotic and somatical distress exists in both groups of patients. In terms of physical activity or physical complaints, amputees often do better than limb saving patients. However, according to the literature $75 \%$ of the amputees report difficulties in developing relations with the opposite sex, whereas hardly any of the limb salvage patients do [229]. Also $75 \%$ of the amputees feel embarrassed to show their prostheses and restrict themselves in certain social activities. This does not occur in limb salvage patients. It is obvious that future research on the quality of life of bone cancer survivors should include prospective evaluation of body image and self-esteem and its impact on social skills.

\section{Closing remarks and prospects for the future}

When reviewing the past 20 years, one has to admit that the improvements in musculoskeletal oncology are impressive. Diagnostic imaging has made major steps forward and local and systemic treatment has also improved, due to progress in histopathology, chemotherapy, radiotherapy, surgery and bioengineering. World-wide scientists, physicians and surgeons are trying to develop and use grading systems and instruments to measure the outcome of treatment and quality of life. It is obvious that these achievements in primary musculoskeletal oncology will be of benefit to the treatment of metastatic bone 
disease in other tumors [230]. Many options are available in chemotherapeutic and radiotherapeutic regimens as well as methods of reconstruction after resection. To make it more complex, combinations of different regimens and methods are increasingly used. Limb salvage has experienced a big boom in the last decade; progress has been made in different methods of treatment, however now the time has come to reconsider the achievements. The development of more methods of treatment, without a reappraisal of what has been achieved, may lead to a further divergence of protocols, without benefit to the goal of optimal oncological and functional outcome in limb saving surgery.

All participating disciplines should come to a consensus with respect to the instruments that are used for measuring; this concerns histopathology, tumor grading, outcome of chemotherapy protocols and outcome of surgery. The biological behaviour of the tumor has only recently been the subject of prospective studies. New developments in molecular biology, genetics and DNA content are providing important tools in the prediction of behaviour, and the outcome of these studies will most probably have an impact on treatment strategies [207]. Tumor response to adjuvant therapy can be monitored, but the efficacy of the present methods should be improved. Positron emission tomography, magnetic resonance spectroscopy and gadolinium enhanced MRI might serve this purpose.

In addition orthopaedic surgeons should aim to prevent local complications in relation to reconstructions, e.g., infection and fractures of allografts and loosening of endoprostheses. Further investigations in the immunological status of allografts [207] should be instituted as well as studies aimed at understanding the biological conduct of endoprosthetic reconstruction. These studies call for cooperation with scientists in the fields of immunology and biomechanics.

In the past major steps forward have been made with respect to soft tissue coverage at the time of reconstruction. Still we are often faced with deficient soft tissues, a situtation needing new techniques which should be developed in close cooperation with plastic reconstructive surgeons.

Through a multidisciplinary approach the treating physicians and surgeons should more than in the past set up a proper time schedule for each category of patients - with adaptation for the individual patient - in order to reduce the risk of complications.

Finally, one has to ascertain whether the variety of reconstructions yields functional [207,231,232] and psychological outcomes that are superior to amputative surgery [233].

In this respect the position of the rotation plasty $[64,207,234]$ is of great interest. A study of this requires large groups of patients, the world-wide use of the same measuring instruments and close cooperation with psychologists and bioengineers. Essentially further pro- gress in limb saving surgery can be anticipated by a multidisciplinary approach, based on a reappraisal of achievements and further developments of new techniques. However major steps forward in complex areas, for instance in tumors of the axial skeleton, call for the utmost ingenuity, which will most probably be the result of individual brainwaves. Therefore, limb salvage still is an art.

\section{Reviewer}

This paper was reviewed by Jeffrey J. Eckardt, M.D., University of California School of Medicine (UCLA), Los Angeles, CA 90024, USA.

\section{References}

[1] Enneking WF. The place of resection in bone tumor surgery. In: Chao EYS, Ivins JC, cds. Tumor Prostheses for Bone and Joint Reconstruction. New York: Thieme Stratton Inc., 1983; 329.

[2] Cade S. Osteogenic sarcoma, a study based on 133 patients. J R Coll Edinburgh 1:79, 1955.

[3] Nilsonne U. Kardinska Hospital experience with bone and joint reconstruction after tumor resection. In: Chao EYS, Ivins JC, eds. Tumor Prostheses for Bone and Joint Reconstruction. New York: Thieme Stratton Inc., 1983; 105-109.

[4] Oldhoff J, Schraffordt Koops H, Nielsen HKL, Van Vries JA. Femur osteosarcoma, treated by HDMTX, resection and reconstruction with a custom-made endoprosthesis. In: Chao EY, Ivins JC, eds. Tumor Prostheses for Bone and Joint Reconstruction. New York: Thieme Verlag, 1983; 141.

[5] Scales JT, Wright KWJ. Major bone and joint replacement using custom implants. In: Chao EYS, Ivins JC, eds. Tumor Prostheses for Bone and Joint Reconstruction. New York: Thieme Stratton Inc., 1983; 149.

[6] Merle d'Aubigne R, Dejournay JP. Diaphyse-epiphyseal resections for bone tumors at the knee. J Bone Joint Surg 40B:385, 1958.

[7] Nilsonne UF. Use of internal hemipelvectomy to preserve the leg. In: Chao EYS, Ivins JC, eds. Tumor Prostheses for Bone and Joint Reconstruction. New York: Thieme Stratton Inc., $1983 ; 35$.

[8] Ottolenghi CE. Massive osteo and ostearticular bone grafts: technique and results of 62 cases. Clin Orthop 87:156-164, 1972.

[9] Mankin HJ, Fogelson FS, Thrasher AZ, Jaffer E. Massive resection and allograft replacement in the treatment of malignant bone tumors. N Eng J Med 294:1247-1255, 1976.

[10] Herndon $\mathrm{CH}$, Chase JW. The fate of massive autogenous and homogeneous bone grafts including articular surfaces. Surg Gynecol Obstet 98:273-290, 1954.

[11] Pho RWA. Free vascularised fibular transplant for replacement of lower radius. J Bone Joint Surg 61B:362-365, 1979.

[12] Seeger LL, Gold RH, Chandnani VP. Diagnostic imaging of osteosarcoma. Clin Orthopaed Related Res 270:254-264, 1991.

[13] Rosen G, Tan C, Sammanochai A, Beattie EJ, Marcove RC, Murphy ML. The rationale for multidrug chemotherapy in the treatment of osteogenic sarcoma. Cancer 35:936, 1975.

[14] Rosen G. Ewing sarcoma: 10-year experience with adjuvant chemotherapy. Cancer 47:2204, 1981.

[15] Rosen G, Caparros B, Huvos AG et al. Pre-operative chemotherapy for osteogenic sarcoma: selection of postoperative adjuvant chemotherapy based on the response to pre-operative chemotherapy. Cancer 49:1221-1230, 1982. 
[16] Suit HD, Mankin HJ, Schiller AL et al. Results of treatment of sarcoma of soft tissue by radiation and surgery at Massachusetts General Hospital. Cancer Treat Symp 3:43-47, 1985.

[17] Suit HD, Mankin HJ, Wood WC, Proppe KH. Preoperative, intraoperative, and postoperative radiation in the treatment of primary soft tissue sarcoma. Cancer 55:2659-2667, 1985.

[18] Codman EA. Registry of bone sarcoma. Surg Gyn Obstet 42:381, 1926.

[19] Lodwick GS. Solitary malignant tumours of bone: the application of predictor variables in diagnosis. Sem Röntgenol 1:293, 1966.

[20] Hogeboom WR, Hoekstra HJ, Mooyaart EL et al. MRI or CT in the preoperative diagnosis of bone tumors. Eur J Surg Oncol 18:67-73, 1992.

[21] Simon MA, Kirchner PT. Scintigraphic evaluation of primary bone tumors. J Bone Joint Surg 62A:758-764, 1980.

[22] Levine E, Lee KR, Heff JR et al. Comparison of computed tomography and other imaging modalities in the evaluation of musculoskeletal tumors. Radiology 131:431-437, 1979.

[23] Manfield P, Mandley AA. Medical imaging by NMR. Br J Radiol 60:188-194, 1977

[24] Berquist ThH. Magnetic resonance imaging of musculoskeletal neoplasms. Clin Orthop 244:101, 1989

[25] Simon MA, Finn HA. Diagnostic strategy for bone and soft tissue tumors. J Bone Joint Surg 75A:622-632, 1993.

[26] Falk S, Alpert M. Five-year survival of patients with Ewing's sarcoma. Surg Gynecol Obstet 124:319-324, 1967.

[27] Lange B, Levine AS. Is it ethical not to conduct a prospectively controlled trial of adjuvant chemotherapy in osteosarcoma? Cancer Treat Rep 66:1699-1704, 1982.

[28] Kilman JW, Clatworthy HW Jr, Newton WA Jr. Reasonable surgery for rhabdomyosarcoma: a study of 67 cases. Ann Surg 178:346-351, 1973.

[29] Pinkel D. Actinomycine $D$ in childhood cancer: a preliminary report. Pediatrics 23:342-347, 1959.

[30] Haddy TB, Nora AH, Sutow WW, Vietti TJ. Cyclophosphamide treatment for metastatic soft tissue sarcoma: intermittent large doses in the treatment of children. Am J Dis Child 114:301-308, 1967.

[31] Sutow WW. Vincristine (NSC-67574) therapy for malignant solid tumors in children (except Wilms' tumor). Cancer Chemother Rep 52:485-487, 1968.

[32] Bode U, Levine AS. The biology and management of osteosarcoma. In: Levine AS, ed. Cancer in the Young. New York: Masson Publishing, 1982; 575-602.

[33] Bonnadonna G, Monfardini S, Delena M, Fossati-Bellani F, Beretta G. Phase I and preliminary Phase II evaluation of adriamycine (NSC-123127). Cancer Res 30:2572-2582, 1970.

[34] Cortes EP, Holland JF, Wong JJ. Amputation and adriamycin in primary osteosarcoma. N Eng J Med 291:998, 1974.

[35] Jaffe N, Farber S, Traggis D. Favorable response of metastatic osteogenic sarcoma to pulse high-dose methotrexate with citrovorum rescue and radiation therapy. Cancer 31:1367-1373, 1973

[36] Jaffe N, Frei E, Traggis D, Bishop Y. Adjuvant methotrexate and citrovorum factor treatment of osteogenic sarcoma. N Engl J Med 291:994-997, 1974

[37] Jaffe N, Frei E, Traggis D, Watts $H$. Weekly high-dose methotrexate-citrovorum factor in osteogenic sarcoma. Presurgical treatment of primary tumor and overt metastases. Cancer 39:45-50, 1977.

[38] Vries JA, Schraffordt Koops H. Nieuwe opvattingen over de behandeling van het Ewing sarcoom. Ned Tijdschr Geneeskunde 119(7):261, 1976.

[39] Schraffordt Koops M, Oldhoff J, Van der Ploeg E, Stam HC, Vermey A, De Vries JA. Nieuwe aspecten bij de behandeling van maligne bottumoren. 22e Jaarboek kankeronderzoek en kankerbestrijding, 1973; 17

[40] Bramwell VHC. Adjuvant chemotherapy in soft tissue and bone sarcomas. In: Oosterom van AT, Unnik JA, eds. Management of Soft Tissue and Bone Sarcomas. New York: Raven Press, 1986; 215.

[41] van der Eyken JW. European Osteosarcoma Intergroup, an interim analysis of surgical data. In: Yamamuro T, ed. New Developments in Limb Salvage in Musculoskeletal Tumors. Heidelberg: Springer Verlag, 1989; 121.

[42] den Heeten GJ, Schraffordt Koops H, Kamps WA, Oosterhuis JW, Sleijfer DTh, Oldhoff J. Treatment of malignant fibrous histiocytoma of bone. Cancer 56:37, 1985.

[43] Enneking WF, Spanier S, Goodman MA. A system for the surgical staging of musculoskeletal sarcoma. Clin Orthop 153:106, 1980.

[44] Enneking WF. A system for staging muscoloskeletal neoplasms. Clin Orthop 204:9-24, 1986.

[45] Enneking WF. Modification of the system for functional evaluation of the surgical management of musculoskeletal tumors. In: Enneking WF, ed. Limb Salvage in Musculoskeletal Oncology. New York: Churchill Livingstone, 1987; 626.

[46] Enneking WF, Dunham W, Gebhardt M, Malawer M, Pitchard DJ. A system for the functional evaluation of reconstructive procedures after surgical treatment of tumors of the musculoskeletal system. Clin Orthop 286:241, 1993.

[47] Kotz R, Salzer M. Rotation plasty for childhood osteosarcomas of the distal part of the femur. J Bone Joint Surg 64A:959, 1982.

[48] Salzer M, Knahr K, Kotz R, Kristen H. Treatment of osteosarcoma of the distal femur by rotation plasty. Arch Orthop Traum Surg 99:131, 1981.

[49] Winkelman W. Rotation plasty for malignant tumors of femur and tibia. In: Yamamuro T, ed. New Developments in Limb Salvage in Musculoskeletal Tumors. Heidelberg: Springer Verlag, 1989; 153-158.

[50] Veth RPH, Nielsen HKL, Oldhoff J et al. The treatment of primary tumors of the femur with chemotherapy (if indicated), resection and reconstruction with an endo-prosthesis. J Surg Oncol 30:252-258, 1985.

[51] Veth RPH, Nielsen HKL, Oldhoff $J$ et al. Megaprostheses in the treatment of primary malignant and metastatic tumors in the hip region. J Surg Oncol 40:214-218, 1989.

[52] Bamberg M, Hoffman W. Soft tissue sarcomas in adults - current treatment strategies. Int J Cancer 57:143-145, 1994.

[53] Herbert SH, Corn BW, Solin LJ et al. Limb-reserving treatment for soft tissue sarcomas of the extremities. The significance of surgical margins. Cancer 72:1230-1238, 1993.

[54] Schajowicz F. Tumors and Tumorlike Lesions of Bone and Joints. New York: Springer Verlag, 1981; 66.

[55] van der Heul RO. Histological grading and typing of osteosarcomas. In: van Oosterom AT, Unnik JAM, eds. Management of Soft Tissue and Bone Sarcomas. New York: Raven Press, 1986; 233.

[56] Enzinger FM, Weiss SW. General considerations. In: CV, ed. Soft Tissue Tumors, 2nd Edition. St. Louis: Mosby Company, $1988 ; 8-14$

[57] Weiss SW, Sobin LH. Histological typing of soft tissue tumors. In: International Histological Classification of Tumors. World Health Organization. Berlin: Springer-Verlag, 1994.

[58] Hashimoto H, Diamaru Y, Takeshita S, Tsuneyshi M, Enjoji M. Prognostic significance of histologic parameters of soft tissue sarcomas. Cancer 70:2816-2822, 1992

[59] Bauer HC, Kreicbergs A, Silferswärd C. Prognostication including DNA analysis in osteosarcoma. Acta Orthop Scand 60:353-360, 1989

[60] Kreicbergs A, Boquist L, Borssen B, Larsson SE. Prognostic 
factors in chondrosarcoma. A comparative study of cellular DNA content and clinicopathologic features. Cancer 50:577-583, 1982.

[61] Donjuijsen K. Mitosis count: reproducibility and significance in grading of malignancy. Human Pathol 17:1122-1125, 1986.

[62] Ueda T, Aozasa K, Tsujimoto $M$ et al. Prognostic significance of $\mathrm{Ki}-67$ reactivity in soft tissue sarcomas. Cancer 63:1607-1611, 1988.

[63] Oda $Y$, Hashimoto H, Takeshita S, Tsuneyoshi M. The prognostic value of immunohistochemical staining for proliferating cell nuclear antigen in synovial sarcoma. Cancer 72:478-485, 1993.

[64] Huvos AG. Bone Tumors Diagnosis, Treatment and Prognosis. Philadelphia: WB Saunders, 1979.

[65] Yunis JJ. Genetic analysis in soft tissue tumors. Lab Invest 70:279-280, 1994.

[66] Limon J, Mroze K, Mandahl N et al. Cytogenetics of synovial sarcoma. Presentation of ten new cases and review of the literature. Genes Chrom Cancer 3:338-345, 1991.

[67] Turc-Carel C, Limon J, Dal Cin P et al. Cytogenetic studies of adipose tissue tumors. Recurrent translocation $t(12 ; 16)$ (q13;p11) in myxoid liposarcomas. Cancer Genet Cytogenet 23:291-299, 1986.

[68] Douglass EC, Valentine M, Etcubanas E et al. A specific chromosomal abnormality in rhabdomyosarcoma. Cytogenet Cell Genet 45:148-155, 1987.

[69] Wang Wuu S, Soukup S, Ballard E et al. Chromosomal analysis of sixteen human rhabdomyosarcomas. Cancer Res 48:893-897, 1988.

[70] Turc-Carel C, Aurias A, Mugneret F et al. Chromosomes in Ewing's sarcoma. An evaluation of 85 cases and remarkable consistency of $\mathrm{t}(11 ; 12)$ ( $\mathrm{q} 24 ; \mathrm{q} 12)$. Cancer Genet Cytogenet 32:229-238, 1988.

[71] Mugneret F, Lizard S, Aurias A et al. Chromosomes in Ewing's sarcoma. II. Non-random additional changes, trisomy 8 and der (16)t(1;16). Cancer Genet Cytogenet 32:239-245, 1988.

[72] Douglass EC, Rowe ST, Valentine $M$ et al. A second nonrandom translocation der $(16) t(1 ; 16)(q 21 ; q 13)$ in Ewing sarcoma and peripheral neuroectodermal tumor. Cytognet Cell Genet 53:87-90, 1990.

[73] Mandahl N, Heim S, Willen $\mathrm{H}$ et al. Characteristic karyotypic anomalies identify subtypes of malignant fibrous histiocytoma. Genet Chrom Cancer 1:9-14, 1989.

[74] Fletcher JA, Kozakewich HP, Hoffer FA et al. Diagnostic relevance of clonal cytogenetic aberrations in malignant softtissue tumors. N Engl J Med 324:436-442, 1991.

[75] Sandberg AA, Turc-Carel C, Gemmill RM. Chromosomes in solid tumors and beyond. Cancer Res 48:1049-1059, 1988.

[76] Bauer HCF, Kreicbergs A, Tribulait B. DNA content prognostic in soft tissue sarcoma: 102 patients followed for 1-10 years. Acta Othorp Scand 62:187-194, 1991.

[77] Sklar J. Principles of molecular cell biology of cancer: molecular approaches to cancer diagnosis. In: de Vita VT, Hellman S, Rosenberg SA, eds. Cancer Principles and Practice of Oncology. Philadelphia: JB Lippincott Company, 1993; 92-113.

[78] Lancien G, Martin-Dupont A, Pen Y, Loget P, Le Noan G. Osteosarcoma, evaluation of prognosis (flow cytometric examination of DNA nuclei). International Symposium on Limb Salvage, St. Malo, France, 1989; Abstract 171.

[79] Kreicbergs A, Tribukait B, Willems J, Bauer HC. DNA flow analysis of soft tissue tumors. Cancer 59:128-133, 1987.

[80] Mankin HJ, Gebhardt MC, Springfield DS. Flow cytometric studies of human osteosarcoma. Clin Orthop Related Res 270:169-181, 1991.

[81] van den Berg E, van Oven MW, de Jong B et al. Comparison of cytogenetic abnormalities and deoxyribonucleic acid ploidy of benign, borderline malignant and different grades of malignant soft tissue tumors. Lab Invest 3:307-313, 1994.

[82] Pastel-Levy C, Bell DA, Rosenberg AE, Preffer F, Colvin LB, Flotte TJ. DNA flow cytometry of epithelioid sarcoma. Cancer 70:2823-2826, 1992.

[83] Alvegard TA, Berg NO, Baldetorp B et al. Cellular DNA content and prognosis of highgrade soft tissue sarcoma: the Scandinavian sarcoma group experience. J Clin Oncol 8:538-547, 1990.

[84] Xiang J, Spanier SS, Benson NA, Braylan RC. Flow cytometric analysis of DNA in bone and soft tissue tumors using nuclear suspensions. Cancer 59:1951-1958, 1987.

[85] Mandahl N, Baldetorp B, Fernö $M$ et al. Comparative cytogenetic and DNA flow cytometric analysis of 150 bone and soft tissue tumors. Int J Cancer 53:358-364, 1993.

[86] Schmidt RA, Conrad EU, Collins C, Rabinovitch P, Finney A. Measurement and prediction of the short-term response of soft tissue sarcomas to chemotherapy. Cancer 72:2593-2601, 1993.

[87] Kreicbergs A, Zetterberg A, Söderberg G. The prognostic significance of nuclear DNA content in chondrosarcoma. Analyt Quant Cytol 4:272-279, 1980.

[88] Hanna S-L, Parham DM, Fairclough DL, Meyer WH, Le AH, Fletcher BD. Assessment of osteosarcoma response to preoperative chemotherapy using dynamic FLASH Gadolinium DTPA enhanced MR mapping. Invest Radiol 27:367-373, 1992.

[89] Redmond OM, Stack JP, O'Connor NG et al. 31P MRS as an early prognostic indicator of patient response to chemotherapy. Magn Reson Med 25:30-44, 1992.

[90] Nieweg OE, Hoekstra HJ, Pruim J, Schraffordt Koops $H$, Oldhoff J, Paans AMJ. Detection and in vivo grading of soft tissue sarcomas with positron emission tomography. $\mathrm{Br} \mathrm{J}$ Surg 80:68, 1993.

[91] Enneking WF. The issue of biopsy. J Bone Joint Surg 64A:1119-1120, 1980.

[92] Den Heeten GJ, Oldhoff J, Oosterhuis JW, Schraffordt Koops H. Biopsy of bone tumours. J Surg Oncol 28:247-251, 1985.

[93] Simon MA, Biermann J. Biopsy of bone and soft tissue lesions. J Bone Joint Surg 75A:616-621, 1993.

[94] Springfield DS, Goodman MA. Biopsy of musculoskeletal lesions. Orthopedics 3:868-870, 1980.

[95] Malawer MM, Link MP, Donaldson SS. Sarcoma of bone. In: de Vita VT, Hellman S, Rosenberg SA, eds. Cancer Principles and Practice of Oncology. Philadelphia: JB Lippincott Company, 1993; 1509-1566.

[96] Barth $\mathrm{R}$ et al. A prospective study of the value of core needle biopsy and fine needle biopsy in the diagnosis of soft tissue sarcoma. Surgery 112:536-543, 1992.

[97] Nesbit ME, Gehan EA, Burgert EO et al. Multimodal therapy of primary non-metastatic Ewing's sarcoma of bone: a longterm follow-up of the First Intergroup Study. J Clin Oncol 8:1664-1676, 1990.

[98] Burgert EO, Nesbit ME, Garnsey LA et al. Multimodal therapy for the management of non-pelvic localized Ewing's sarcoma of bone: Intergroup Study IESS-II. J Clin Oncol 8:1514-1524, 1990.

[99] Jürgens $H$, Exner U, Gadner $\mathrm{H}$ et al. Multidisciplinary treatment of Ewing's sarcoma of bone. A 6-year experience of a European Cooperative Trial. Cancer 61:23-32, 1988.

[100] Bacci G, Ferrari S, Avella M et al. Non-metastatic Ewing's sarcoma: results in 98 patients treated with neoadjuvant chemotherapy. Ital J Orthop Traumatol 17:449-465, 1991.

[101] Craft AW, Jürgens H. EICESS-92 protocol, Newcastle upon Tyne, Münster, May 1992 (Unpubished).

[102] Craft AW, Cotterrill S, Imeson J. Improvement in survival for Ewing's sarcoma by substitution of ifosfamide for cyclophos- 
phamide. A UKCCSG/MRC Study. Am J Pediatr Hematol Oncol 15 (Suppl A):S31-S35, 1993.

[103] Miser JS, Kinsella TJ, Triche TJ et al. Ifosfamide with mesna uroprotection and etoposide: an effective regimen in the treatment of recurrent sarcomas and other tumors of children and young adults. J Clin Oncol 5:1191-1198, 1987.

[104] Bacci G, Picci P, Ruggieri $P$ et al. No advantages in the addition of ifosfamide and VP-16 to the standard four-drug regimen in the maintenance phase of neoadjuvant chemotherapy of Ewing's sarcoma of bone: results of two sequential studies. J Chemother 5:247-257, 1993.

[105] Kropej D, Schiller C, Ritschl P et al. The management of IIB osteosarcoma: experience from 1976 to 1985 . Clin Orthop Related Res 270:40-45, 1991.

[106] Meyers PA, Heller G, Healy J et al. Chemotherapy for nonmetastatic osteogenic sarcoma: the Memorial Sloan-Kettering experience. J Clin Oncol 10:5-15, 1992.

[107] Postma A, Kamps WA, Schraffordt Koops H, Veth RPH, Göeken LNH, Molenaar WM. Osteosarcoma of the limb, an institutional report of 10 years. Cancer Treat Res 62:361-364, 1993.

[108] Rosen G, Caparros B, Huvos AG, Kostoff C. Preoperative chemotherapy for osteogenic sarcoma. Cancer 49:1221, 1982.

[109] Link MP. Adjuvant therapy in the treatment of osteosarcoma. In: de Vita VT, Hellman S, Rosenberg SA, eds. Advances in Oncology. Philadelphia: JB Lippincott, 1986; 193-207.

[110] Bacci G, Picci P, Pignatti G et al. Neoadjuvant chemotherapy for non-metastatic osteosarcoma of the extremities. Clin Orthop Related Res 270:87-99, 1991.

[111] Frassica FJ, Sim FH, Frassica DA. Survival and management considerations in postirradion osteosarcoma and Paget's osteosarcoma. Clin Orthop Related Res 270:120, 1991.

[112] Rosenberg S, Chabner BA, Young RC et al. Treatment of osteogenic sarcoma: I. Effect of adjuvant high-dose methotrexate after amputation. Cancer Treat Rep 63:739-751, 1979.

[113] Rosen G, Marcove RC, Caparros B. Primary osteogenic sarcoma. The rationale for preoperative chemotherapy and delayed surgery. Cancer 43:2163, 1979.

[114] Rosen G. Role of chemotherapy in the management of bone and soft tissue sarcomas. In: Coombs R, Friedlaender G, eds. Bone Tumor Management. London: Buttelworths, 1987; 290.

[115] Ferrari S, Sassoli V, Orlandi $M$ et al. Serum methotrexate (MTX) concentrations and prognosis in patients with osteosarcoma of the extremities treated with a multidrug neoadjuvant regimen. J Chemother 5:135-141, 1993.

[116] Winkler K, Bielack SS, Delling G, Jürgens H, Kotz R, SalzerKuntschik M. Treatment of osteosarcoma: experience of the Cooperative Osteosarcoma Study Group (COSS). Cancer Treat Res 62:269-277, 1993.

[117] Solheim OP, Saeter G, Elomaa I, Alvegard TA. The treatment of osteosarcoma: present trends. The Scandinavian Sarcoma Group experience. Ann Oncol 3 (Suppl 2):S7-S11, 1992.

[118] Bramwell VHC, Burgess M, Sneath R et al. A comparison of two short intensive adjuvant chemotherapy regimens in operable osteosarcoma of limbs in children and young adults: the first study of the European Osteosarcoma Intergroup. J Clin Oncol 10:1579-1591, 1992.

[119] Jaffe N. Pediatric osteosarcoma: treatment of the primary tumor with intraarterial cis-diamminedichloroplatinum-II (CDP) - advantages, disadvantages, and controversial issues. Cancer Treat Res 62:75-84, 1993.

[120] Benjamin RS, Chawla SP, Carrasco CH et al. Preoperative chemotherapy for osteosarcoma with intravenous adriamycine and intra-arterial cisplatinum. Ann Oncol 3 (Suppl 2):S3-S6, 1992.

[121] Quintana J, Beresi V, Del Pozo H et al. Intra-arterial cisplatin given prior to surgery in osteosarcoma: grade of necrosis and size of tumor as major prognostic factors. Am J Pediatr Hematol Oncol 13:269-273, 1991.

[122] Bacci G, Picci P, Ferrari S et al. Prognostic significance of serum alkaline phosphatase measurements in patients treated with adjuvant and neoadjuvant chemotherapy. Cancer 71:1224-1230, 1993.

[123] Rehan N, Bieling $P$, Winkler $P$ et al. Die prognostische Bedeuting des Tumorvolumens beim Osteosarkom unter neoadjuvanter Chemotherapie. Klin Pädiatr 205:200-209, 1993.

[124] Huvos AG, Rosen G, Marcove RC. Primary osteogenic sarcoma: pathologic aspects in 20 patients after treatment with chemotherapy, en bloc resection, and prosthetic bone replacement. Arch Pathol Lab Med 101:114, 1977.

[125] Davis AM, Bell RS, Goodwin PJ. Prognostic factors in osteosarcoma: a critical review. J Clin Oncol 12:423-431, 1994.

[126] Bacci G, Picci P, Ferrari S et al. Influence of adriamycine dose in the outcome of patients with osteosarcoma treated with multidrug neoadjuvant chemotherapy: results of two sequential studies. J Chemother 5:237-246, 1993.

[127] Malawer M, Buch R, Reaman $G$ et al. Doxorubicin on the choice of surgical procedure for high-grade bone sarcomas of the extremities. Clin Orthop Related Res 270:214-223, 1991.

[128] Miser JS. Ifosfamide in the treatment of bone tumors in children and young adults. Am J Pediatr Hematol Oncol 15 (Suppl A):S27-S30, 1993.

[129] Goren MP, Wright RK, Pratt CB et al. Potentiation of ifosfamide neurotoxicity, hematotoxicity, and tubular nephrotoxicity by prior cisdiaminedichloro-platinum (II) therapy. Cancer Res 47:1457-1460, 1987.

[130] Stevens M, Flamant F, Praquin MT. Treatment of nonmetastatic rhabdomyosarcoma in the SIOP MMT 89 study. Med Pediatr Oncol 20:389, 1992.

[131] Ortega JA, Ragab AH, Gehan EA et al. A feasibility, toxicity, and efficacy study of ifosfamide, actinomycine $\mathrm{D}$, vincristine for the treatment of childhood rhabdomyosarcoma. A report of the Intergroup Rhabdomyosarcoma Study IV pilot study. Am J Pediatr Hematol Oncol 15 (Suppl A):S15-S20, 1993.

[132] Treuner J. Ifosfamide in the treatment of soft-tissue sarcoma. Experience of the German Cooperative Soft Tissue Sarcoma Studies. Am J Pediatr Hematol Oncol 15 (Suppl A):S21-S26, 1993.

[133] Godzinski J, Flamant F, Rey A, Praquin MT, Martelli H. Value of postchemotherapy bioptical verification of complete clinical remission in previously incompletely resected (stage I and II pT3) malignant mesenchymal tumors in children: International Society of Pediatric Oncology 1984 Malignant Mesenchymal Tumors Study. Med Pediatr Oncol 22:22-26, 1994.

[134] Elias AD, Antman KM. Adjuvant chemotherapy for soft tissue sarcoma: an approach in search of an effective regimen. Semin Oncol 16:305-311, 1989.

[135] Mazanet R, Antman KH. Adjuvant therapy for sarcomas. Semin Oncol 18:603-612, 1991.

[136] Bramwell VH, Mouridsen H, Santoro A et al. Cyclophosphamide versus ifosfamide: final report of a randomized phase II trial in adult soft tissue sarcomas. Eur $\mathbf{J}$ Cancer Clin Oncol 23:311-321, 1987.

[137] Yang JC, Gladstein EJ, Rosenberg SA et al. Sarcomas of soft tissue. In: de Vita VT, Hellman S, Rosenberg SA, eds. Cancer Principles and Practice of Oncology. Philadelphia: JB Lippincott, 1993; 1436-1488.

[138] Gottlieb JA, Benjamin RS, Baker LH. Role of DTIC (NSC45338) in the chemotherapy of sarcomas. Cancer Treat Rep 60:199-203, 1976.

[139] Buesa JM, Mouridsen HT, van Oosterom AT et al. High dose DTIC in advanced soft tissue sarcomas of the adult. Proc 5th NCI-EORTC N Drug Symp 2:21, 1986. 
[140] Lienard D, Ewalenko P, Delmotte JJ, Renard N, Lejeune FJ. High-dose recombinant tumor necrosis factor alpha in combination with interferon gamma and melphalan in isolation perfusion of the limbs for melanoma and sarcoma. J Clin Oncol 10:52-60, 1992.

[141] Hoekstra HJ, van Ginkel RJ, Nieweg OE et al. Evaluation of tumor metabolism and response to hyperthermic isolated regional perfusion with tumor necrosis factor alpha, interferon gamma and melphalan for soft tissue sarcoma with FDG positron emission tomography (abstract). Proc Am Soc Clin Oncol 474, 1994.

[142] Donaldson SS. A story of continuing success - radiotherapy for Ewing's sarcoma. Int J Radiat Oncol Biol Phys 7:279-281, 1981.

[143] Kinsella TJ, Lichter AS, Miser J et al. Local treatment of Ewing's sarcoma: radiation therapy versus surgery. Cancer Treat Rep 68:695-701, 1984.

[144] Dunst J, Sauer R, Burgers JMV et al. Radiation therapy as local treatment in Ewing's sarcoma. Results of the cooperative Ewing's sarcoma studies CESS 81 and CESS 86. Cancer 67:2818-2825, 1991.

[145] Göbel V, Jürgens H, Etspüler $G$ et al. Prognostic significance of tumor volume in localized Ewing's sarcoma of bone in children and adolescents. J Cancer Res Clin Oncol 113:187-191, 1987.

[146] Brown AP, Fixsen JA, Plowman PN. Local control of Ewing's sarcoma: an analysis of 67 patients. Br J Radiol 60:261, 1987.

[147] Donaldson SS, Shuster J, Andreozzi C. The Pediatric Oncology Group (POG) experience in Ewing's sarcoma of bone. Med Pediatr Oncol 17:283, 1989.

[148] Glasser DB, Lane JM. Stage IIB osteogenic sarcoma. Clin Orthop Related Res 270:29-40, 1991.

[149] Goorin AM, Andersen JW. Experience with multiagent chemotherapy for osteosarcoma: improved outcome. Clin Orthop Related Res 270:22-29, 1991

[150] Lane JM, Hurson B, Boland PJ, van Glasser DB. Osteogenic sarcoma. Clin Orthop 204:93, 1986.

[151] Martinez A, Goffinet DR, Donaldson SS, Bagchaw MA, Kaplan HS. Intra-arterial infusion of radiosensitizer (BUdR) combined with hypofractionated irradiation and chemotherapy for primary treatment of osteogenic sarcoma. Int $\mathbf{J}$ Radiat Oncol Biol Phys 11:123-128, 1985.

[152] Kinsella TJ, Glatstein E. Clinical experience with intravenous radiosensitizers in unresectable sarcomas. Cancer 59:908-915, 1987.

[153] Slater JD, McNeese MD, Peters LJ. Radiation therapy for unresectable soft tissue sarcomas. Int J Radiat Oncol Biol Phys 12:1729, 1986

[154] Tepper JE, Suit HD. Radiation therapy alone for sarcoma of soft tissue. Cancer 56:475, 1985.

[155] Tepper J, Suit H. Radiation therapy of soft tissue sarcomas. Cancer 55:2273-2277, 1985.

[156] Gunderson LL, Nagorney DM, Mcllrath DC et al. External beam and intraoperative electron irradiation for locally ad. vanced soft tissue sarcomas. Int J Radiat Oncol Biol Phys 25:647-656, 1993.

[157] Willet CG, Suit HD, Tepper JE et al. Intraoperative electron beam radiation therapy for retroperitoneal soft tissue sarcoma. Cancer 68:278-283, 1991.

[158] Kinsella TJ, Sindelar WF, Lack E et al. Preliminary results of a randomized study of adjuvant radiation therapy in resectable adult retroperitoneal soft tissue sarcomas. J Clin Oncol 6:18-25, 1988.

[159] Harrison LB, Franzese F, Gaynor JJ, Brennan MF. Long-term results of a prospective randomized trial of adjuvant brachytherapy in the management of completely resected soft tissue sarcomas of the extremity and superficial trunk. Int $\mathbf{J}$ Radiat Oncol Biol Phys 27:259-265, 1993.
[160] Shiu MH, Hilaris BS, Harrison LB, Brennan MF. Brachytherapy and function - saving resection of soft tissue sarcoma arising in the limb. Int $\mathbf{J}$ Radiat Oncol Biol Phys 21:1485-1492, 1991.

[161] Lindberg R. Treatment of localized soft tissue sarcomas in adults at M.D. Anderson Hospital and Tumor Institute (1960-1981). Cancer Treat Symp 3:59-65, 1985.

[162] Enneking WF, McAuliffe JA. Adjunctive preoperative radiation therapy in treatment of soft tissue sarcomas: a preliminary report. Cancer Treat Symp 3:37-42, 1985.

[163] Potter DA, Kinsella T, Glatstein E et al. High-grade soft tissue sarcomas of the extremities. Cancer 58:190-205, 1986.

[164] Lindberg RD, Martin RG, Romsdahl MM, Barkley HT. Conservative surgery and postoperative radiotherapy in 300 adults with soft-tissue sarcomas. Cancer 47:2391-2397, 1981.

[165] Marcove RC, Stovell PB, Huvos AG, Bullough PB. The use of cryosurgery in the treatment of low and medium grade chondrosarcomas. Clin Orthop 122:147, 1977.

[166] Malawer MM, Marks MR, Chesney D, Piasio D, Gunther SF, Schmeckler BM. The effect of cryosurgery and PMMA in dogs with experimental bone defects, comparable to tumor defects. Clin Orthop 226:229-310, 1988.

[167] Hackbarth DA. Resections and reconstructions for tumors of the distal radius. Orthop Clin North Am 22:49-65, 1991.

[168] Kotz R. Tumorendoprothesen bei malignen kochentumoren. Orthopäde 22:160-166, 1993.

[169] Ustri M, Naito J, Yamashita M, Yamamuro M. Microsurgical reconstruction in limb salvage procedures. J Reconstr Microsurg 9:91-101, 1993.

[170] Eckardt JJ, Eilber FR, Rosen $G$ et al. Endoprosthetic replacement for stage IIB osteosarcoma. Clin Orthop Related Res 270:202-214, 1991.

[171] Linberg BE. Interscapulo-thoracic resection for malignant tumors of the shoulder joint region. J Bone Joint Surg 10:344-349, 1928

[172] Malawer MM, Sugarbaker PH. Shoulder girdie resection: the Tikhoff Limberg procedure and its modifications. In: Sugarbaker, ed. Surgery in Musculoskeletal Cancer. New York: Thieme Verlag, 1992; 346-361.

[173] Eckardt JJ, Eilber FR, Riyaz HJ, Mirra JM. Endoprosthetic replacement of the scapula, including the shoulder joint, for malignant tumors: a preliminary report. In: Enneking WF, ed. Limb Salvage in Musculoskeletal Oncology. New York: Churchill Livingstone, 1987; 542.

[174] Sim FH, Frassica FJ, Wold LE, McLeod RA. Chondrosarcoma of the spine, Mayo clinic experience. In: Sundaresan N, ed. Tumors of the Spine. Philadelphia: WB Saunders Company, 1990; 155-162.

[175] Sundaresan N, Schiller AL, Rosenthal DI. Osteosarcoma of the spine. In: Sundaresan N, ed. Tumors of the Spine. Philadelphia: WB Saunders Company, 1990; 128-145.

[176] Eilber FR, Eckardt JJ, Grant TG. Resection of malignant bone tumors of the pelvis. In: Enneking WF, ed. Limb Salvage in Musculoskeletal Oncology. New York: Churchill Livingstone, 1987; 136-141.

[177] Tomeno B, Languepin A, Gerber C. Local resection with limb salvage for the treatment of periacetabular bone tumors. In: Enneking WF, ed. Limb Salvage in Musculoskeletal Oncology. New York: Churchill Livingstone, 1987; 147-156.

[178] Enneking WF. Musculoskeletal Tumor Surgery. The Pelvis New York: Churchill Livingstone, 1983; 483-490.

[179] Campanacci M, Capanna R. Closing remarks on periacetabular reconstruction. In: Enneking WF, ed. Limb Salvage in Musculoskeletal Oncology. New York: Churchill Livingstone, 1987; 187-192.

[180] Enneking WF, Dunham WK. Resection and reconstruction for primary neoplasms involving the innominate bone. $J$ Bone Joint Surg 60A:731-746, 1978. 
[181] Leung PC. Bone reconstruction using vascularized bone grafts. In: Yamamuro T, ed. New Developments in Limb Salvage in Musculoskeletal Tumors. Tokyo: Springer Verlag, 1989; 431-437.

[182] Dunham WK. Acetabular resection for sarcoma. In: Enneking WF, ed. Limb Salvage in Musculoskeletal Oncology. New York: Churchill Livingstone, 1987; 170-184.

[183] Campanacci M, Capanna R. Pelvic resections, the Rizzoli Institute experience. Orthop Clin North Am 22:65-87, 1991.

[184] Capanna R, Guernello N, Ruggieri R et al. Periacetabular pelvic resection. In: Enneking WE, ed. Limb Salvage in Musculoskeletal Oncology. New York: Churchill Livingstone, 1987; 141-147.

[185] Lane JM, Duane K, Glasser DB et al. Periacetabular resections for malignant sarcomas. In: Enneking WF, ed. Limb Salvage in Musculoskeletal Oncology. New York: Churchill Livingstone, 1987; 166-170.

[186] Alho A et al. Allograft replacement in aggressive and malignant bone tumors. In: Langlais F, Tomeno B, eds. Limb Salvage. Berlin: Springer Verlag, 1982; 41-45.

[187] Enneking WF. Closing Remarks. International Symposium on Limb Salvage, St. Malo, France, Session 11, 1989 (Unpublished).

[188] Nielsen HKL, Veth RPH, Oldhoff J, Schraffordt Koops H, Scales JT. Resection of a peri-acetabular chondrosarcoma and reconstruction of the pelvis. A case report. J Bone Joint Surg 67B:413-415, 1985.

[189] Veth RPH, Nielsen HKL, Oldhoff J et al. Resection of tumors of the pelvis and proximal femur. In: Yamamuro T, ed. New Developments for Limb Salvage in Musculoskeletal Tumors. Tokyo: Springer Verlag, 1989; 419.

[190] van der Lei B, Hoekstra HJ, Veth RPH et al. The use of the saddle prosthesis for reconstruction of the hip joint after tumor resection of the pelvis. J Surg Oncol 50:216-219, 1992.

[191] Nieder E, Keller A, The saddle prosthesis. II. Endo model. In: Yamamuro T, ed. New Developments in Limb Salvage in Musculoskeletal Tumors. Tokyo: Springer Verlag, 1989; 481-490.

[192] Healey JH, Lane JM, Marcove $\mathrm{K}$ et al. Resection and reconstruction of periacetabular malignant and aggressive tumors. In: Yamamuro T, ed. New Developments in Limb Salvage in Musculoskeletal Tumors. Tokyo: Springer Verlag, 1989; 443-451.

[193] Joyce MJ, Makley JT. Complications in hemipelvic resection. Allograft reconstruction for bone sarcomas. In: Langlais $F$, Tomeno B, eds. Limb Salvage. Berlin: Springer Verlag, 1991; 125-138.

[194] Veth RPH, Schraffordt Koops H, Nielsen HKL et al. A critique of techniques for reconstruction after internal hemipelvectomy for osteosarcoma. Cancer Treat Res 62:221-230, 1993.

[195] Salzer M, Knahr K, Selura J, Btaun O. Resection treatment of malignant pelvic bone tumors. In: Enneking WF, ed. Limb Salvage in Musculoskeletal Oncology. New York: Churchill Livingstone, 1987; 104-112.

[196] Samson IB, Springfield DS, Suit HS, Mankin HJ. Operative treatment of sacrococcygeal chordome. J Bone Joint Surg 75A:1476-1484, 1993.

[197] Uchida A, Hamada H, Yoshikawa $H$ et al. Surgical treatment of bone tumors arising from the pelvic ring. In: Yamamuro T, ed. New Developments in Limb Salvage in Musculoskeletal Tumors. Tokyo: Springer Verlag, 1989: 451-458.

[198] Tomita K, Tsuchiya H, Morikawa S et al. En bloc sacral resection and total sacrotomy. In: Langlais F, Tomeno B, eds. Limb Salvage. Berlin: Springer Verlag, 1991; 655-661.

[199] Pho RWH, Kour AK, Satku K. Local pedicular vascularised bone graft in reconstruction around the knee. In: Langlais $F$, Tomeno B, eds. Limb Salvage. Major Reconstructions in On- cologic and Non-Tumoral Conditions. Berlin: Springer Verlag, 1991; 233.

[200] Yajima H, Tamai S, Misumoto S, Sugimuro M, Horiuchi K. Vascularised fibular graft for reconstruction after resection of aggressive benign or malignant bone tumors. Microsurgery 13:227-233, 1992.

[201] Eckardt JJ, Safran MR, Eilber FR, Rosen G, Kabo JM. Expandable endoprosthetic reconstruction of the skeletally immature after malignant bone tumor resection. Clin Orthop 297:188-202. 1993.

[202] Kenan S, Bloom N, Lewis MM. Limb-sparing surgery in skeletally immature patients with osteosarcoma: the use of an expandable prosthesis. Clin Orthop Related Res 270:223-231, 1991.

[203] Scales JT, Sneath RS, Wright KWJ. Design and clinical use of extending protheses. In: Enneking WF, ed. Limb Salvage in Musculoskeletal Oncology. New York: Churchill Livingstone, $1987 ; 52$.

[204] van Krieken FM, Hartel RM, Campen DH et al. A growth imitating lengthening element for modular femoral endoprosthesis. In: Enneking WF, ed. Limb Salvage in Musculoskeletal Oncology. New York: Churchill Livingstone, 1987; 613.

[205] Verkerke GJ, Schraffordt Koops H, Veth RPH et al. Design of a lengthening element for a modular femur endoprosthetic system. Proc Inst Mech Eng 203:97, 1989.

[206] Verkerke GJ, Schraffordt Koops H, Veth RPH et al. An extendable modular endoprosthetic system for bone tumor management in the leg. J Biomed Eng 91:196, 1990.

[207] Veth RPH. IIB osteosarcoma: current management, local control, and survival statistics - the Netherlands. Clin Orthop Related Res 270:67-71, 1991.

[208] Yaw KM, Wurtz LD. Resection and reconstruction for the proximal tibia. Orthop Clin North Am 22:133-161, 1991.

[209] Gitelis S, Piasecki P. Allograft prosthetic composite arthroplasty for osteosarcoma and other aggressive bone tumors. Clin Orthop Related Res 270:197-202, 1991.

[210] Malawer MM. The use of the gastrocnemius transposition flap with limb sparing surgery for knee sarcomas. In: Kotz R, ed. Proceedings of The Second International Workshop on the Design and Application of Tumor Prostheses for Bone and Joint Reconstruction. Vienna: Egermann, 1983; 270-274.

[211] Kotz R, Pengracz N, Fellinger 1, Pritschl P. Uncemented hinge prosthesis with reinsertion of the ligamentum patellae. In: Yamamuro $T$, ed. New Developments in Limb Salvage in Musculoskeletal Tumors. Tokyo: Springer Verlag, 1989; 605.

[212] van Krieken FM. Methodical Design of a Modular Femur Endoprosthesis. Thesis, University Twente, The Netherlands, 1987 (ISBN 9071382079).

[213] National Institutes of Health, Limb-Sparing Treatment of Soft Tissue Sarcomas and Osteosarcomas. Consensus Development, Vol. 5, No. 6. Bethesda, MD: NIH, 1984.

[214] Ruggieri P, De Cristofaro R, Picci P et al. Complications and surgical indications in 144 cases of non-metastatic osteosarcoma of the extremities, treated with neoadjuvant chemotherapy. Clin Orthop 295:226-238, 1993.

[215] Nielsen HKL, Veth RPH, Oldhoff J et al. Functional results of prosthetic replacements in patients with primary tumors of the distal femur. In: Enneking WF, ed. Limb Salvage in Musculoskeletal Oncology. New York: Churchill Livingstone, 1987; 424.

[216] Gherlinzoni F, Picci P, Bacci G, Campanacci M. Limb sparing versus amputation in osteosarcoma. Clin Oncol 3 (Suppl 2):23-27, 1992.

[217] Tsuchiya $H$, Tomita K. Prognosis of osteosarcoma treated by limb saving surgery. Jpn J Clin Oncol 22:347-353, 1992.

[218] Unwin PS, Cobb JP, Walker PS. Loosening in cemented 
femoral prostheses, a study of 668 tumor cases. In: Brown KL, ed. Complications of Limb Salvage. Montreal: ISOLS, 1991; 133-137.

[219] Gebhardt MC, Flugstad DI, Springfield DS et al. The use of bone allografts for limb salvage in high-grade extremity osteosarcoma. Clin Orthop Related Res 270:181-197, 1991.

[220] Clohisy DR, Mankin HJ. Osteoarticular cellografts for reconstruction after resection of a musculoskeletal tumor in the proximal 2nd of the tibia. J Bone Joint Surg 76A:549-555, 1994

[221] Thompson RC, Pickvance EA, Garry D. Fractures in large seg ment allografts. J Bone Joint Surg 75A:1663-1674, 1994.

[222] Mankin HJ, Doppelt SH, Tomford WW. Clinical experience with allograft implantation. The first 10 years. Clin Orthop 174:69, 1982.

[223] Mankin HJ, Gebhardt MC, Tomford W. Use of frozen cadaveric osteoarticular allografts in the treatment of benign and malignant tumors around the knee. In: Enneking WF, ed. Limb Salvage in Musculoskeletal Oncology. New York: Churchill Livingstone, 1987; 354.

[224] Enneking WF, Mindell ER. Observations on massive retrieved human allografts. J Bone Joint Surg 73A:1123-1142, 1991.

[225] Smeitink J, Verreusel M, Schröder C, Lippens R. Nephrotoxicity associated with ifosfamide. Eur J Pediat 148:164-166, 1988.

[226] Skinner R, Pearson ADJ, Price L, Coulthard MG, Craft AW. Nephrotoxicity after ifosfamide. Arch Dis Child 65:732-738, 1990.

[227] Minow RA, Benjamin RS, Lee ET, Gottlieb JA. Adriamycine cardiotoxicity: risk factors. Cancer 39:1397-1402, 1977.

[228] Sugarbaker PH, Barofski I, Rosenberg SA et al. Quality of life assessment of patients with extremity sarcoma. Surgery 91:17-23, 1987.

[229] Postma A, Kingma A, Veth RPH et al. Quality of life in bone tumour patients comparing limb-salvage and amputation of the lower extremity. J Surg Oncol 51:47-51, 1992.

[230] Veth RPH, Hoekstra HJ, Schraffordt Koops H, Mehta DM, Willemse PHB. Surgical management of metastatic bone disease. In: Sugarbaker PH, ed. Musculoskeletal Surgery for Cancer. Bethesda/New York: NCI/Thieme Medical Publishers, 1992; 375-381.

[231] Frieden RA, Ryniker D, Kenan S, Lewis MM. Assessment of patient function after limb sparing surgery. Arch Phys Med Rehabil 74:38 43, 1993.

[232] Otis JC, Lane JM, Kroll MA, Bachus SU, Healey JH. Kinesiological measurements in patients with various limb salvage or amputation procedures for tumor removal. In: Yamamuro T. ed. New Developments in Limb Salvage in Musculoskeletal Tumors. Tokyo: Springer Verlag, 1989; 3.

[233] Hefti F. Malignant bone tumors. Is amputation still necessary today? Schweiz Rundsch Med Prax 83:307-315, 1993.

[234] van der Eyken JW, Voute PA et al. De behandeling van osteosarcoom van het distal femur door middel van een rotatie plastiek van het onderbeen. Ned Tijdschr Geneeskunde 128:1267, 1984.

[235] Capanna R, Ruggieri P, De Cristofuro R et al. Complications, their treatment and outcome in 257 cementless megaprostheses. In: Brown KL, ed. Complications of Limb Salvage. Montreal: ISOLS, 1991; 147-151.

\section{Biographies}

René P.H. Veth, M.D., Ph.D., was born in 1947. He began his training as an orthopaedic surgeon at the University Hospital, Groningen, The Netherlands in 1977 and graduated from there in 1983. His first contact with limb saving surgery was in 1978 at the division of Surgical Oncology, University Hospital, Groningen. He has been a member of the International Society of Limb Salvage since 1983. Since 1991 he has been Head and Professor of the Department of Orthopaedics, University Hospital, Nijmegen, The Netherlands. Q.G.C.M. van Hoesel, M.D., obtained his medical degree at the State University in Utrecht and trained for Internal Medicine at the Catharina Hospital in Eindhoven and the Department of Internal Medicine of the University Hospital, Utrecht. The Dutch Cancer League granted him a Fellowship at the Dutch National Cancer Institute for training in Medical Oncology. He performed basic research at the Dutch National Institute for Public Health and Environmental Hygiene, which resulted in a thesis entitled 'Activity and reduced toxicity of liposome entrapped doxorubicin'. As a staff member of the Division of Medical Oncology of the Department of Internal Medicine, he has a special interest in soft tissue and bone sarcomas, lung cancer and gynecological cancer. $\mathrm{He}$ is a consultant with the Comprehensive Cancer Centers, East and South. Jos P.M. Bökkerink, Ph.D., M.D., was born in 1948, and has worked since 1979 as a pediatric oncologist at the Center of Pediatric Oncology, South-East Netherlands of the Department of Pediatrics, St. Radboud University Hospital of Nijmegen. Dr. Bökkerink's special interests include pharmacokinetics and biochemical pharmacology of antimetabolites used in leukemia, Wilms' tumor, Langerhans' cell histiocytosis, Ewing's sarcoma, and the practical and theoretical training of medical students. Jacob Hoogenhout, M.D., Ph.D., was born in 1940. He is Radiation Oncologist at the Institute of Radiotherapy, University Hospital, Nijmegen St. Radboud, The Netherlands. His special interests are bone marrow transplantation, haemato-oncology, oncology in children and brachytherapy. Maciej S.M. Pruszczyn$s k i$, M.D., Ph.D., was born in 1937. He is staff pathologist and consultant in surgical pathology at the Department of Pathology of University Hospital, Nijmegen. His field of interest is in orthopaedic pathology, pulmonary pathology and gastrointestinal pathology. 